\title{
La ley tunecina sobre la eliminación de la violencia contra la mujer: la norma y el debate
}

The Tunisian Law on the Elimination of Violence against Women: rules and debates

Carmelo PÉREZ BELTRÁN

Universidad de Granada

carmelop@ugr.es

https://orcid.org/0000-0002-0108-8863

Recibido 7/9/2018. Aceptado para publicación 5/11/2018

Para citar este artículo: Carmelo PÉREZ BELTRÁN (2018), “La ley tunecina sobre la eliminación de la violencia contra la mujer: la norma y el debate"'" en Revista de Estudios Internacionales Mediterráneos, 25, 32-59.

Para acceder a este artículo: https://doi.org/10.15366/reim2018.25.003

\section{Resumen}

Este artículo estudia el contexto social y los debates ideológicos sobre la violencia de género en Túnez que se encuentran articulados en torno a la reciente adopción de la Ley Orgánica 58/2017, del 11 de agosto referente a la eliminación de la violencia contra la mujer. Tomando como idea central el concepto de subalternidad y sus relaciones entre un centro ideológico dominante y la periferia, este trabajo parte de la hipótesis de que la Ley sobre violencia contra las mujeres traduce las dinámicas ideológicas de la sociedad tunecina en su búsqueda por interpretar las narrativas globalizantes eurocéntricas a partir de ciertas prácticas contrahegemónicas de disidencia o resistencia. A partir de ello, el trabajo hace una aproximación a la realidad social de la violencia contra las mujeres en Túnez y analiza la evolución de las estrategias políticas y jurídicas hasta la adopción de la Ley Orgánica 58/2017, la cual es analizada señalando sus principales aportaciones y los principales temas de debate generados.

Palabras clave: Violencia de género / Subalternidad / Mujeres / Túnez

\begin{abstract}
This article examines the social context and ideological debates revolving around the issue of violence against women in Tunisia, particularly in relation to the new Organic Law 58/2017 on the elimination of violence against women, enacted on August 11th 2017. Central to the paper's
\end{abstract}


analysis is the concept of 'subalternity' and the relationships existing between a dominant ideological center

and its periphery. The paper hypothesizes that the law on violence against women is a 'translation' [or reflection] of the ideological dynamics of Tunisian society in its quest to interpret hegemonic Eurocentric narratives through the implementation of certain anti-hegemony practices such as dissidence and resistance. With these ideas, the paper looks at the social reality of violence against women in Tunisia and analyses the evolution of political and juridical strategies up through the enactment of Organic Law 58/2017, pointing out the law's main contributions as well as the topics of debate it has generated.

Keywords: Gender based violence / Subalternity / Women / Tunisia

\section{Introducción}

Como se despende de su último artículo (art. 44), a mediados de febrero del presente año 2018 ha entrado en vigor la Ley Orgánica 58/2017, del 11 de agosto, referente a la eliminación de la violencia contra la mujer, que fue publicada en el Boletín Oficial de la República Tunecina seis meses antes, el día 15 de agosto de 2017; una ley reivindicada desde hacía décadas por la sociedad civil más comprometida con la igualdad de género y con los derechos humanos. Será objeto de este estudio perfilar el contexto, la realidad social y los debates sobre la violencia de género en Túnez, así como el contenido de la Ley Orgánica 58/2017, desde la perspectiva del postorientalismo propuesta por Hamid Dabashi (Dabashi, 2009 y 2012) incidiendo, principalmente, en la idea de la subalternidad (Guha, 2002) que refleja las relaciones de poder entre un centro ideológico dominante (Occidente) y una periferia que se debate entre el seguidismo de las narrativas eurocéntricas y las prácticas contrahegemónicas de disidencia o resistencia, asentadas estas en la reclamación de ciertas especificidades históricas y culturales, principalmente, pero que no siempre son acordes con los valores igualitarios que sustentan los derechos humanos fundamentales.

Estudiar los cambios legislativos, en este caso los relacionados con el género, es de una importancia capital, ya que la Ley tiene una función ambivalente, de tal modo que puede funcionar, y de hecho funciona, como el guardián del orden social, político y moral establecido, del que participa y tiende a reproducir, pero también puede operar como vector de cambio y de evolución de las normas y de los esquemas mentales de la sociedad en la que actúa y pretende transformar. Porque el derecho no solo es acción, sino que también a través de su discurso, su retórica y su lenguaje contribuye decididamente a formar una visión de uno mismo, del otro y del mundo en su globalidad. Teniendo en cuenta estas cuestiones se comprende mejor el importante rol que desempeña la legislación en toda sociedad y la importancia de considerarlo como "un compendio de una cultura social, o un metalenguaje social, un lenguaje social rudimentario pero esencial y central que extrae su fuerza de su activismo e impone sus categorías a los demás discursos sociales" (Henry, 1988: 181).

Teniendo en cuenta lo anterior, este trabajo parte de la hipótesis de que la Ley sobre violencia contra las mujeres traduce las dinámicas ideológicas de la sociedad tunecina en su búsqueda por adaptar y/o interpretar las narrativas globalizantes eurocéntricas. Teniendo esto en cuenta, las 
estrategias contrahegemónicas de disidencia o resistencia a dichas narrativas eurocéntricas hacen que el propio texto legislativo establezca ciertos los límites para seguir conservando los valores ideológicos y culturales considerados como integrantes de la nacionalidad tunecina.

\section{Género, mujer, mujeres: el debate sobre la denominación}

Considerada por algunas fuerzas políticas y sociales como un gran hito en la historia de Túnez, otros sectores opinan, más bien, que se trata de una ley que no logra superar las narrativas eurocéntricas de la post-colonialidad y la subalternidad en la línea de pensamiento que plantea Dabashi (2009), puesto que, según éstos, solo contempla algunos aspectos puntuales y sesgados de la violencia, siguiendo de cerca las dinámicas de ciertos países occidentales, pero que dista mucho de ser una norma integral que garantice la prevención de la violencia de género específica del país, de sus normas y de sus instituciones, como desarrollaremos más adelante. La propia denominación de la Ley incide ya en este conflicto centro-periferia, pues la opción por "violencia contra la mujer" entra en conflicto con otras denominaciones que se han ido imponiendo en el ámbito occidental, tales como "violencia de género" (caso español) o "violencia contra las mujeres" (caso francés) o la más reciente designación de "violencias sexuales y sexistas" que muy recientemente se viene debatiendo en Francia. El debate es largo e imposible de abracar en este estudio, pero lo cierto es que la denominación de la Ley tunecina tiene por referente directo a una de las primeras declaraciones internacionales sobre este tema: la Declaración sobre la Eliminación de la Violencia contra la Mujer (1993), en cuyo primer artículo define la "violencia contra la mujer" como "todo acto de violencia basado en la pertenencia al sexo femenino que tenga o pueda tener como resultado un daño o sufrimiento físico, sexual o psicológico para la mujer, así como las amenazas de tales actos, la coacción o la privación arbitraria de la libertad, tanto si se producen en la vida pública como en la vida privada".

Sin embargo, a partir sobre todo de la IV Conferencia Mundial sobre las Mujeres (Beijin 4-15 de septiembre de 1995), el término "violencia contra las mujeres" convive o, más bien, compite con el de "violencia de género", cuyo uso se empieza a extender y estandarizar, no solo entre las/los teóricas/os de diferentes ámbitos de conocimiento, sino también por parte de las instituciones y organismos oficiales que terminan adoptándolo, entre ellos, el propio gobierno español a través de la Ley Orgánica 1/2004, de 28 de diciembre, de Medidas de Protección Integral contra la Violencia de Género. Esto, sin embargo, provoca numerosos e interesantes debates epistemológicos, como los que mantiene María Luisa Maqueda Abreu (2006) cuando afirma que la denominación "violencia contra las mujeres" que aparece en la DEVM y en otros muchos documentos de diversa naturaleza (leyes, resoluciones, estudios, medios de comunicación...) es ambigua e inadecuada, ya que incide más en la cuestión biológica que en la clave cultural o en la construcción social que el concepto género implica. En palabras de la autora "es una manifestación más de la resistencia que existe a reconocer que la violencia contra las mujeres no es una cuestión biológica sino de género. Se trata de una variable teórica esencial para comprender que no es la diferencia entre los sexos la razón del antagonismo (...), sino que es consecuencia de una situación de discriminación intemporal que tiene su origen en una estructura social de naturaleza patriarcal" (Maqueda, 2006: 2).

Lo cierto es que el término "violencia de género" genera debate y cuenta también con sus detractoras/es (De Luján Piatti, 2013: 26-36) más o menos declaradas/os, quienes no solamente le achacan una excesiva influencia de la lengua inglesa (gender based violence /gender violence), sino que consideran que su utilización sistemática por políticos, instituciones oficiales y demás 
agentes sociales puede llegar a convertir el término en un eufemismo que enmascara una dura realidad. En este sentido incide Silvia Tubert al considerar que existe un uso abusivo del término "género" que puede llegar a encubrir "las relaciones de poder entre los sexos, como sucede cuando se habla de violencia de género en lugar de violencia de los hombres hacia las mujeres: una categoría neutra que oculta la dominación masculina" (Tubert, 2003: 8). En esta misma línea, el Instituto Vasco de la Mujer en su informe Violencia contra las mujeres (Emakunde, 2009), tras señalar la diversidad de términos utilizados para definir una misma realidad, opta por la utilización del término "violencia contra las mujeres", alegando los siguientes motivos: "en primer lugar, es un término claro e inteligible para cualquier persona no experta en la materia, en segundo lugar, hace visible que son las mujeres quienes sufren este tipo de violencia $y$, en tercer lugar, es la expresión que en estos momentos concita un mayor consenso social y político y que se viene utilizando en los instrumentos jurídicos internacionales" (Emakunde, 2009: 2).

El mundo árabe tampoco escapa a esta polémica y debido sobre todo a la influencia hegemónica que ejerce el discurso de los organismos oficiales y otras agencias especializadas sobre las periferias culturales, el término "género" viene siendo traducido por el tecnicismo "naw" que, en realidad, significa "clase, tipo, variedad, especie", a fin de diferenciarlo de la voz "ŷins" que, desde el siglo XIX y debido a la actividad intelectual de las primeras generaciones de feministas árabes, había tomado una connotación más sexual o biológica. Sin embargo, se trata de una reapropiación conflictiva, no bien asumida por todas/os las/los especialistas en el tema, como es el caso de Ben Achour (2016: 6) quien considera que, en realidad, es "ŷins" el término que mejor recoge el sentido de "construcción distintiva" de un grupo con respecto a otro, debido a lo cual de esta misma raíz (ŷ-n-s) deriva el término ŷinsiyya (nacionalidad), es decir, el distintivo que diferencia a un grupo nacional de otro no-nacional. Lo cierto es que el término "naw", a pesar de que actualmente sea utilizado por ciertas organizaciones de la sociedad civil, está aún lejos de convertirse en parte integrante del vocabulario de los estudios feministas del mundo árabe "no por el rechazo de sus claves de análisis teórico sobre la construcción de las distinciones sociales y relacionales entre masculino y femenino, sino más bien debido a la resistencia a lo que parece ser un tipo de terminología de las ciencias sociales pretendidamente "neutral" y disociada de la política" (Ben Achour, 2006: 6-7). Frente a una nomenclatura que es percibida desde la subalternidad como imposición cultural y como lazo ideológico poscolonial, muchas de las/los investigadoras /es siguen optando hoy día por "mujeres" en plural, en vez de la voz "género".

La cuestión del número gramatical no es un asunto baladí. En este sentido, la opción de la Ley tunecina por el singular (mujer/al-mar'a) conlleva una carga ideológica que, desde los márgenes, también mantiene fricciones con el centro del debate feminista occidental y hegemónico que, al menos desde los años 80 del siglo XX, había incidido en el carácter monolítico, ficticio y abstracto del término "mujer" (en singular), el cual se definía esencialmente frente al concepto "hombre". Sin embargo, el término en plural (mujeres), que surge muy relacionado con el desarrollo de los feminismos periféricos (raza, clase, identidad, colonialidad, fronteras...), hace referencia, según esta línea de pensamiento, a los sujetos históricos, a la diversidad de realidades y a la heterogeneidad de experiencias y vivencias entre las propias mujeres (Amorós y De Miguel, 2005; Badran, 2012; Butler, 1990, bell hooks, 2004). Podríamos cuestionarnos por qué, entonces, la Ley tunecina sigue manteniendo el número singular del término cuando, además, las intelectuales feministas tunecinas suelen optar por el plural, como hemos indicado anteriormente. En este sentido, son varias las posibilidades de respuesta que podríamos barajar. Una de ellas incide en la 
toma de conciencia del carácter subalterno o subordinado del sujeto histórico magrebí (Bhabha, 2013; Dabashi 2009) frente a un centro ideológico y cultural occidental que es percibido como impositor. En palabras de Macías Amoretti (2018) "las voces de la subalternidad toman cuerpo y reclaman un espacio por sí mismas y no en relación con la transformación cultural o la evolución histórica del otro". Es por ello por lo que el sentido de conciencia nacional y de especificidad cultural musulmana adquieren un carácter unitario que, en el caso de la Ley que estamos tratando, se expresaría mejor con el singular: la mujer (tunecina y musulmana). No obstante, esto puede disfrazar una realidad siempre cambiante, compleja y heterogénea, ya que las violencias basadas en el género no son actos singulares ni aislados, sino fenómenos estructurales $y$ sistemáticos que pueden afectar a todas las mujeres, independientemente de su estatus social, su posición económica, su religiosidad y su formación intelectual. Frente a esta idea, la especificidad religiosa musulmana ha sido invocada por ciertos sectores sociales como garantía para explicar que "contrariamente a las sociedades occidentales donde las costumbres son relajadas y la moral desenfrenada, el compromiso de la población con sus creencias le impide cometer acciones como la violación, el incesto o la pedofilia" (Cherif, 2008: 111), lo cual dista mucho de la realidad, como intentaremos señalar a lo largo de este trabajo. Idea esta que convive con otra visión más economicista, a la que se ha solido adherir el régimen oficial, según la cual, aunque se reconoce la existencia de violencia contra las mujeres, sin embrago "representa un hecho marginal que solo afecta a los medios socioeconómicos desfavorecidos. Su motivo no sería la misoginia sino la miseria y, por tanto, desaparecerá con su eliminación" (Cherif, 2008: 111), opinión más que cuestionable teniendo en cuenta la realidad social no solo de Túnez sino de cualquier sociedad.

Pero, además de ello, la opción de la Ley Orgánica 58/2017 por la denominación "eliminación de la violencia contra la mujer" deja al margen otro tipo de manifestaciones violentas que también están directamente relacionadas con los valores de dominación y discriminación que sustentan las estructuras patriarcales de la sociedad y su modelo familiar, y que atentan contra los derechos humanos más fundamentales. Nos referimos a la violencia física, moral, psicológica, institucional y sexual a la que se ven sometidas las personas lesbianas, gays, bisexuales, transgénero e intersexuales (LGTBI) que, como comentaremos más adelante, se encuentran criminalizadas en el propio Código Penal tunecino. En este caso, las especificidades históricas, culturales y nacionales de la sociedad magrebí, basadas en una rígida e inalterable concepción binaria de la orientación sexual y de la identidad de género (hombre/mujer, virilidad/feminidad) parecen prevalecer sobre cualquier otra opción, aunque ello conlleve el sufrimiento y la discriminación de seres humanos y de ciudadanos/as tunecinos.

\section{Una aproximación a la violencia contra las mujeres en Túnez antes de la Revolución de los Jazmines}

La visibilización de la violencia contra las mujeres y el debate social y político en torno a ello están directamente relacionados con el desarrollo del movimiento feminista de Túnez y su lucha favor del empoderamiento de las mujeres y la igualdad de género en todos los ámbitos de la vida pública y privada. Aunque las primeras voces pueden remontarse a finales de los años 70 del pasado siglo XX, en el marco de la reflexión y el debate que emanaban del Club Tahar al-Haddad (1979-1989), sin embargo será sobre todo a partir de los años 90 cuando la violencia contra las mujeres deja de ser percibida como un asunto privado para convertirse en una de las principales preocupaciones sociales, directamente relacionada con la violación de los derechos humanos, en cuya lucha debe estar implicada tanto la sociedad civil como las diferentes instituciones del 
Estado. A ello contribuyó de forma decisiva el surgimiento de asociaciones con un marcado cariz feminista y reivindicativo (Ghanmi 1993), que hicieron de la violencia de género y de la feminización de la pobreza uno de sus principales caballos de batalla, como la Asociación Tunecina de Mujeres Demócratas (ATFD ), la Asociación de Mujeres para la Investigación y el Desarrollo (AFTUR ), creadas ambas en 1989, así como otras asociaciones intermagrebíes muy activas en la época, como el Colectivo Maghreb-Egalité 95 (CME95), fundado en 1992 (Mahfoudh, 2014). Igualmente, por esta época fue adoptada la Declaración sobre la Eliminación de la Violencia contra la Mujer (DEVM), aprobada por la Asamblea General de las Naciones Unidas el 20 de diciembre de 1993 (Resolución 48/104), a la que se adscribirá la mayor parte de los movimientos de lucha señalados. Entre otras aportaciones importantes, esta Declaración no solamente definía la violencia contra la mujer en función a la pertenencia al sexo femenino, como hemos señalado anteriormente, sino que distinguía tres principales manifestaciones de dicha violencia dependiendo del ámbito en la que esta se produce (art. 2): la violencia física, sexual y psicológica que se produce en el marco familiar (malos tratos, abuso sexual de las niñas, violación por el marido, mutilación genital femenina, explotación, etc.); la violencia física, sexual y psicológica cometida en el espacio público (violación, abuso sexual, acoso e intimidación en el trabajo, en instituciones educacionales y en otros lugares, trata de mujeres, prostitución forzada); y finalmente, la violencia física, sexual y psicológica perpetrada o tolerada por el Estado.

Sin lugar a duda, la campaña de sensibilización puesta en marcha en 1991 bajo el lema de "La violencia es una indignidad y el silencio un error" (Ben Achour, 2016: 10) y, especialmente, la creación en 1993 del "Centro de escucha y de orientación de las mujeres víctimas de la violencia" (Jouini y Kari, 2017: 5), ambas a iniciativa de la ATFD, supusieron uno de los mayores hitos por el debate sociopolítico alcanzado y la experiencia adquirida. Por primera vez, la violencia de género dejaba de ser una preocupación exclusiva de algunas asociaciones de mujeres y empezaba a alcanzar una mayor visibilidad y concienciación en los medios de comunicación, en los debates políticos, en los objetivos y actividades de la sociedad civil comprometida con los derechos humanos, en las deliberaciones del cuerpo de jueces, médicos y abogados, y en la concienciación de la propia ciudadanía tunecina.

Debido a toda esta gran actividad llevada a cabo durante las décadas precedentes, que tuvo una importancia capital para visibilizar y tomar conciencia sobre este grave problema social, el tema de la violencia contra las mujeres es asumido por las propias instituciones gubernamentales en la primera década del siglo XXI, siempre bajo el paraguas y la estrecha colaboración y/o tutelaje de organismos e instituciones internacionales como ONU Mujeres, Fondo de Naciones Unidas para la Población o diversas agencias de cooperación al desarrollo, entre ellas, la española. Es por ello por lo que, desde un principio, surgen voces de resistencia a una realidad que es percibida como subalterna o subordinada al centro de la ideología hegemónica occidental y que, como contrapartida, reclaman un espacio propio y autónomo a las dinámicas sociales e históricas del otro. En este marco hay que situar la puesta en marcha en 2008 de la denominada "Estrategia Nacional de lucha contra la violencia contra las mujeres", impulsada desde Ministerio de Asuntos de la Mujer, la Familia y la Infancia", encabezado en aquel entonces por Sarra Kanoun Jarraya, y contando, en esta ocasión, con el partenariado del Fondo de Naciones Unidas para la Población. Para ello se creó una comisión nacional a fin de evaluar los servicios de apoyo y asesoramiento a las víctimas de los que disponían las instituciones públicas y las asociaciones de la sociedad civil, y 
de analizar el marco jurídico del país que afectaba a la violencia de género (Amnesty International, 2015: 78; Chachem y Ammar, 2016: 2).

En buena medida, la denominada Revolución de los jazmines (2010-2011) supuso una paralización temporal de los trabajos en curso de esta Estrategia Nacional, aunque resurgirán con fuerzas renovadas poco después. Sin embargo, los meses previos a las revueltas fueron importantes, ya que permitieron llevar a cabo una importante encuesta a nivel nacional que, por primera vez, aportaba datos estadísticos objetivos y fiables sobre la amplitud, la naturaleza y las consecuencias de la violencia contra las mujeres, como primera premisa para llevar a cabo una luchar eficaz para su erradicación. Se trata de la Enquête nationale sur la violence à l'égard des femmes en Tunisie, realizada durante el año 2000 por un nutrido grupo multidisciplinar bajo la dirección y supervisión de la Oficina Nacional de la Familia y la Población, dependiente del Ministerio de la Salud Pública. También en esta ocasión un organismo extranjero actuaba de promotor y guía, puesto que la mencionada Enquête nationale se llevó a cabo en el marco del proyecto de cooperación "Promoción de la equidad de género y prevención de la violencia contra las mujeres", financiado por la Agencia Española de Cooperación Internacional. La encuesta, bajo la coordinación científica de Habiba Zéhi Ben Romdhane, Profesora de la Facultad de Medicina de la Universidad de Túnez, tenía varios objetivos, el primero de los cuales consistía en hacer una estimación, lo más exacta posible, sobre la prevalencia de la violencia contra las mujeres (violencia verbal, psicológica, física, económica y sexual) durante toda la vida de estas y en los últimos doce meses. Junto a ello, otros objetivos importantes eran (ONFP, 2010: 15): analizar los determinantes de la violencia, identificar los perfiles de mujeres especialmente vulnerables a la violencia, analizar los efectos de la violencia sobre la salud y la calidad vida de las mujeres, estudiar el papel de la familia y los amigos, y analizar la reacción de las mujeres frente a situaciones de violencia. En total fueron encuestadas 3.873 mujeres, de 18 a 64 años de edad y de todo el territorio nacional; la mayoría de ellas casadas $(66,25)$, amas de casa $(73,1 \%)$ y residentes en medio urbano $(68,1 \%)$ (ONFP, $2010: 23)$.

Sin ánimo de ser exhaustivos es preciso señalar los principales resultados obtenidos, ya que servirán de base para la futura actividad gubernamental y no gubernamental en torno a la violencia de género, incluyendo la necesidad de adoptar medidas legislativas. Quizás el dato más significativo sea que casi la mitad de las mujeres encuestadas (exactamente el 47,6\%) declararon haber sufrido algún tipo de violencia a lo largo de su vida, sin que apenas existan diferencias significativas entre el medio ( $47,1 \%$ en medio urbano y $48,7 \%$ en medio rural), el nivel de estudios o la actividad profesional, aunque ciertamente las más mujeres que parecen estar más expuestas son: las mujeres rurales, amas de casa y con nivel básico de estudios o analfabetas (ver gráfico 1 y 2).

(\%)

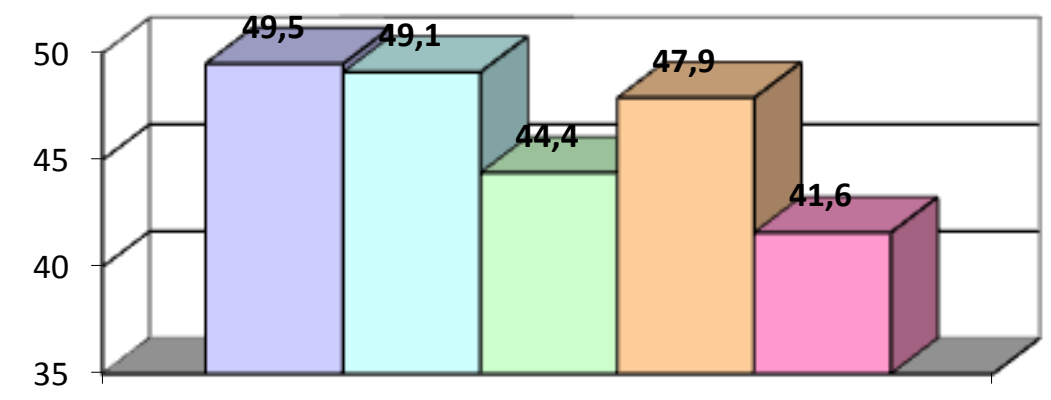

$\square$ Anafabetas $\square$ Primaria $\square$ Colegial $\square$ Secundaria $\square$ Superior 
(\%)

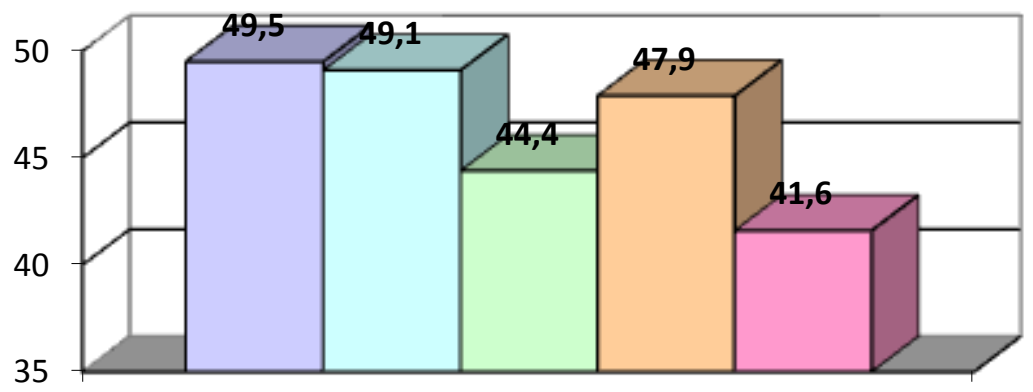

$\square$ Analfabetas $\square$ Primaria $\square$ Colegial $\square$ Secundaria $\square$ Superior

Fig. 1: Prevalencia de la violencia contra las mujeres según el nivel de instrucción. Fuente: Realización propia a partir de los datos de ONFP (2010: 38)
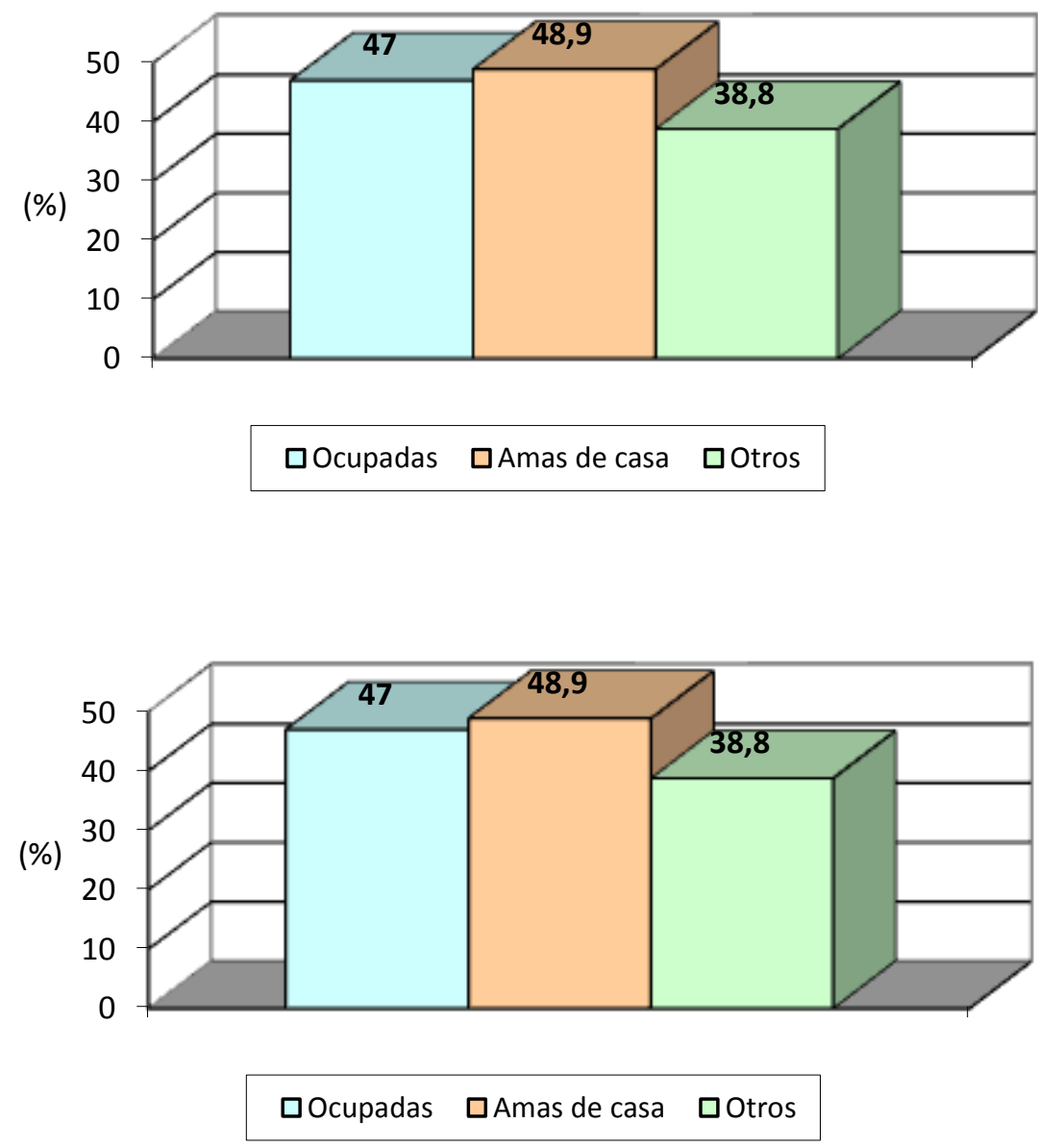

Fig. 2: Prevalencia de la violencia contra las mujeres según actividad económica. Fuente: Realización propia a partir de los datos de ONFP (2010: 38) 
También resultan interesantes los resultados obtenidos sobre el tipo de violencia a la que más frecuentemente se ven sometidas las mujeres tunecinas que, de manera visual, quedan recogidos en el Gráfico 3.

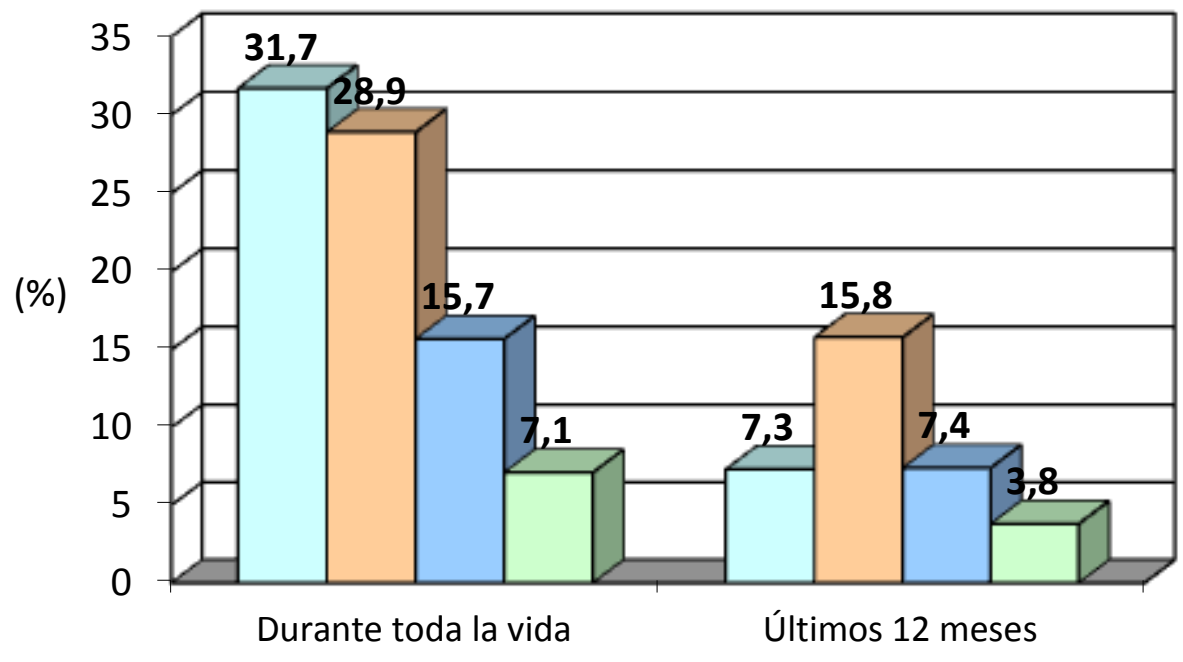

$\square$ Física $\square$ Psicológica $\square$ Sexual $\square$ Económica

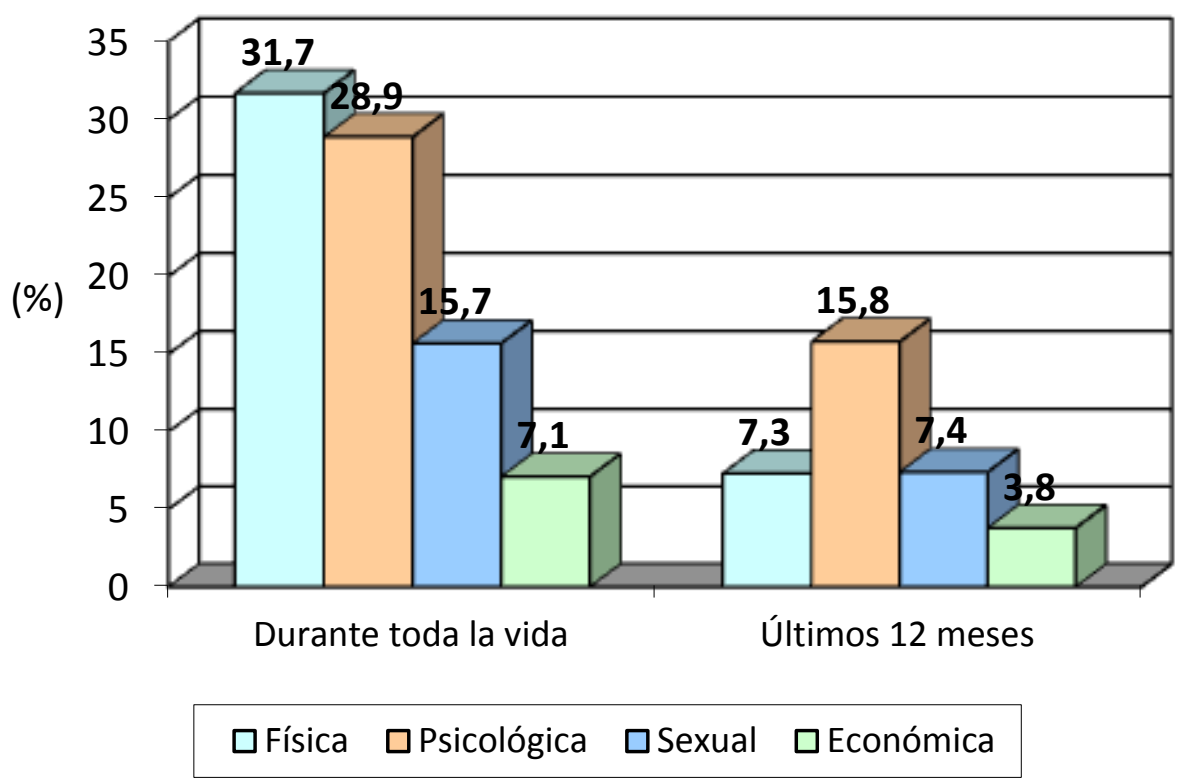

Fig. 3: Prevalencia de la violencia contra las mujeres según tipo de violencia. Fuente: Realización propia a partir de los datos de ONFP (2010: 39)

Si tenemos en cuenta la experiencia vital de las mujeres en su totalidad, la violencia física es la más frecuente, con un $31,7 \%$ de las encuestadas, seguida de cerca por la psicológica (28,9\%), aunque en el curso del último año las experiencias violentas de tipo psicológico (insultos, intimidación, humillación, menosprecio, etc.) dobla literalmente a la primera señalada. Teniendo esto en cuenta, la encuesta revela igualmente que es la pareja sentimental (esposo, novio, etc.) el principal autor de todo tipo de violencia contra las mujeres, sobre todo de la violencia psicológica 40 
(68,5\%) y sexual (78,2\%), aunque también lo es de la violencia física con un $47,2 \%$ de las respuestas. Junto al marido, el resto de los miembros de la familia (padres, hermanos, otros miembros) se muestran como los principales autores de la violencia física (43\%), mientras que en el caso de la psicológica este porcentaje desciende hasta el $16,7 \%$. Solamente en el caso de la violencia sexual (relaciones sexuales forzadas o no consentidas, violación, abuso, etc.,) existe un significativo porcentaje del $21,3 \%$ de autores no pertenecientes al ámbito familiar (ONFP, 2010: 41). De todo ello se deduce que es la violencia intrafamiliar $y$, especialmente, la conyugal en el ámbito doméstico la que mayor prevalencia tiene dentro de la sociedad tunecina, el menos en lo referente a sus manifestaciones físicas y psicológicas más extremas.

Aunque la encuesta aporta otra serie de datos de gran interés solo vamos a destacar dos últimos asuntos de interés que son constatados en la Enquête nationale como son: la soledad de las mujeres víctima y normalización de la violencia. En el primer caso, los resultados avalaban la idea de que un porcentaje muy elevado $(42,1 \%)$ de las mujeres que habían sufrido algún tipo de violencia no habían pedido ningún tipo de ayuda y ni siquiera habían confiado su lamentable situación a sus familiares más allegados o a sus amistades (ONFP, 2010: 58). Y de aquí se desprende la segunda cuestión apuntada: la mayor parte de las mujeres agredidas optan por el silencio y no llegan a interponer denuncia alguna porque la violencia y las relaciones de desigualdad son asumidas, toleradas y normalizadas por gran parte de la sociedad patriarcal de Túnez, incluyendo a las propias víctimas, de tal forma que el $55 \%$ de las encuestadas declaran que la violencia intrafamiliar constituye un hecho usual, ordinario, "normal", del que ni siquiera merece la pena hablar (ONFP, 2010: 58).

Estos datos son solo aproximativos de una dura realidad, anclada en la cotidianidad de muchas mujeres tunecinas que sufren en silencio y abnegadamente diversos actos de violencia física, moral o psicológica, incluidas las amenazas, las coacciones, las agresiones a su libertad sexual o la privación arbitraria de su libertad. A ello se añaden otros factores, como la estigmatización social de las víctimas, la dependencia económica de éstas, los complejos procesos judiciales, el miedo al rechazo familiar, la falta de una intervención ágil y adecuada de la policía, la escasez de centros de acogida y otras infraestructuras de apoyo a las víctimas, las presiones familiares y la consideración de la violencia intrafamiliar como un "asunto privado", entre otros motivos que no podemos abordar en profundidad este trabajo. Lo que sí es cierto es que este documento revelaba una situación muy preocupante y, de hecho, su contenido no fue dado a conocer hasta después de la Revolución de los Jazmines.

\section{La violencia de género tras la Revolución de los Jazmines}

Tras las revueltas del 2010-2011, el debate sobre la violencia de género no solo no desaparece de la escena política y pública, sino que alcanza dimensiones mucho mayores, fruto del cual será la adopción de la Ley Orgánica 58/2017, del 11 de agosto, referente a la eliminación de la violencia contra la mujer.

La primera acción destacada fue el relanzamiento en 2012 desde instancias gubernamentales de la Estrategia Nacional de lucha contra la violencia contra las mujeres, a la que ahora se le añadía la apostilla de "a través del ciclo de vida", la cual seguía estando apoyada por Fondo de Naciones 
Unidas para la Población. Con los objetivos de contribuir a los logros de la revolución del 14 de enero de 2011 en términos de igualdad, equidad y libertad; preservar los derechos de las mujeres y luchar contra toda forma de discriminación de estas en el marco de los compromisos internacionales adquiridos por Túnez, esta Estrategia Nacional se articula en cuatro ejes principales (Stratégie, 2012: 14-25): a) recopilación de datos e información sobre la violencia contra la mujer; b) mejora de la calidad y la disponibilidad de servicios psicosociales y de salud para las víctimas; c) movilización social y sensibilización para poner fin a la estigmatización de las víctimas y transformar la percepción que tiene la sociedad sobre la violencia contra las mujeres; d) lucha para la revisión de la legislación a fin de prevenir y combatir todas las formas de violencia contra las mujeres. No obstante, muchos de estos objetivos apenas si son puestos en marcha debido a falta de recursos humanos y económicos, puesto que hay que tener en cuenta que en el año 2017, el Ministerio de la Mujer, la Familia, la Infancia y la Tercera Edad recibía solamente el $0,27 \%$ de los presupuestos generales del Estado para llevar a cabo toda su actividad, incluyendo la lucha contra la violencia de género

En el marco de esta Estrategia Nacional, este último punto sobre la necesidad de adoptar una ley orgánica de violencia de género alcanza una gran dimensión y se convierte en una acción prioritaria a alcanzar a corto plazo. En general, el debate sobre este proyecto de ley se articula en torno a una serie de cuestiones, entre las cuales destacan: la necesidad de lograr un consenso político entre las diferentes tendencias ideológicas del país en torno a un proyecto de ley orgánica sobre violencia de género que acabe con las disposiciones discriminatorias que existen en la ley; la urgencia de llevar a cabo una campaña de sensibilización intensiva que logre movilizar la opinión pública, y la conveniencia de promocionar medicas intersectoriales de prevención, protección y asistencia para las víctimas (Ghachem y Ammar, 2006: 3-4).

En esta época, el debate sobre la violencia de género se encuentra íntimamente relacionado con la adopción de la nueva constitución que debía regir los designios del país tras la caída del régimen de Ben Ali (Martínez Fuentes, 2011) y que fue aprobada el 26 de enero de 2014 por la Asamblea Constituyente que había sido elegida el 23 de octubre de 2011, obteniendo la mayoría de escaños el partido islamista Ennahda (89 escaños, 37\%), liderado por Rashid Gannushi. El proceso de elaboración del proyecto constitucional fue muy intenso y dio lugar a todo tipo de debates de gran calado, pero en lo que a nuestro tema respecta, tres fueron los principales aspectos que causaron gran controversia: la presencia de la sharîa en la Constitución, la complementariedad de los sexos y el lenguaje inclusivo.

En cuanto al primer tema, al menos desde febrero de 2012 circulaba de manera oficiosa el proyecto constitucional propuesto por el partido Ennahda en cuyo artículo 10 se estipulaba que "La sharîa es la principal fuente de legislación" (Ben Achour, 2016: 16), lo cual provocó apasionados debates sobre los fundamentos de la identidad nacional, la naturaleza civil del Estado, la discriminación jurídica de las mujeres en la shari’a y la conformidad de toda norma del derecho positivo con las prescripciones inmutables y categóricas de la ley islámica. Tras semanas de una apasionada "la guerra de identidad" , esta idea acabó siendo descartada en pro del consenso y la unidad (Martínez Fuentes, 2013: 43) y el propio Gannushi afirmaba: "el antiguo artículo primero de la Constitución, según el cual Túnez es un estado libre, independiente y soberano cuyo idioma es el árabe y cuya religión es el islam, es objeto de consenso y es suficiente para expresar el sistema de referencia del islam en términos de legislación en Túnez" (Ben Achour, 2016: 17).

También el tema de la complementariedad de roles tuvo que ser descartado del proyecto constitucional de Ennahda. Concretamente, el artículo 28.2 del capítulo referente a los derechos y 
libertades dictaba: "El estado protege los derechos de la mujer y apoya sus logros, puesto que ella es socio (šarīk) del hombre en la construcción de la nación, cuyos roles son complementarios (takāmul) dentro de la familia ". La idea que prevalece en este pensamiento, muy usual dentro del islamismo, es que "mujeres y hombres son complementarios por su propia naturaleza y, por tanto, los roles sociales entre hombres y mujeres también deben complementarios (...) La idea de base sostenida por el discurso islamista es que Dios ha creado a mujeres y hombres como seres diferentes, en cuanto a su naturaleza, con el objetivo de que se complementen mutuamente. Por tanto, las relaciones entre hombres y mujeres no son construcciones sociales sujetas al devenir histórico; son un proyecto divino que debe permanecer inmutable en el tiempo y el espacio" (Pérez y Macías, 2017: 21). Sin embargo, para los sectores más laicos de la sociedad, la complementariedad es la ideología patriarcal que sustenta la desigualdad y la discriminación al establecer un sistema jerárquico y diferencial que legitima diversos tipos de violencia de género. Por todo ello, debe ser excluida de la identidad nacional tunecina en pro de las ideas de igualdad que emanan de la Declaración Universal de Derechos Humanos y de otras convenciones internacionales. En todo caso, esta experiencia demuestra la capacidad de adaptación, ajuste y pragmatismo del partido Ennahda, aunque, como señala Guadalupe Martínez, tanto este tema como el anterior generó no sólo la más absoluta fractura con la tendencia laica de la sociedad tunecina, sino también "la frustración del ala más conservadora de sus representantes en la Asamblea y de sus notables en el organigrama interno" (Martínez Fuentes, 2013: 43), muchos de los cuales optaron por abandonar esta formación en favor de otras más acordes con su visión ultraconservadora.

Finalmente, el debate sobre el lenguaje inclusivo en la Constitución fue objeto de grandes controversias. Si bien el sector más apegado al feminismo defendía con ahínco un lenguaje inclusivo y no sexista con el objetivo de visibilizar a la mitad de la población, las mujeres, y de que los presupuestos igualitarios del discurso simbólico y jurídico puedan promocionar una sociedad igualmente paritaria y no violenta, sin embargo esta propuesta contó con la férrea oposición de otros sectores sociopolíticos, que consideraban este asunto, más bien, como una moda impuesta por las tendencias más radicales del feminismo occidental y de organizaciones internaciones que buscan la globalización cultural sin respetar las identidades locales. Aunque de nuevo la guerra identitaria estaba servida, la Constitución de 2014 introduce en numerosas ocasiones expresiones inclusivas, aunque no de forma sistemática, mediante la repetición simultánea de los términos en masculino y en femenino. De este modo, el preámbulo señala que "el Estado garantiza (...) la igualdad de todos los ciudadanos (al-muwāținīn) y las ciudadanas (al-muwāțināt) en derechos y deberes"; el artículo 21, "Los ciudadanos y las ciudadanas son iguales en derechos y deberes (...). El Estado garantiza a los ciudadanos y ciudadanas las libertades y los derechos individuales y colectivos"; el artículo 40, "Todo ciudadano (al-muwāțin) y ciudadana (al-muwāțina) tiene derecho al trabajo"; en incluso, en el artículo 74 referente a la presidencia de la república antepone el femenino al masculino: "La candidatura a la presidencia de la República es un derecho para toda electora (nājiba) o elector (nājib)...". Junto a ello, otras referencias van destinadas exclusivamente a las mujeres, como ocurre en el segundo párrafo del artículo 34: "El Estado garantizará la representatividad de la mujer en las asambleas elegidas"; y en la mayor parte del artículo 46: "El Estado se compromete a proteger los derechos adquiridos de las mujeres y garantizar su consolidación y promoción. El Estado garantiza la igualdad de oportunidades entre hombres y mujeres para acceder a diversas responsabilidades y en todas las áreas. El Estado trabaja para establecer la paridad entre mujeres y hombres en las asambleas elegidas. El estado tomará las 
medidas necesarias para eliminar la violencia contra las mujeres". Para el tema que nos ocupa, este último artículo tiene una importancia capital, ya que hace una referencia expresa a la eliminación de la violencia contra las mujeres, visibilizando en la carta magna esta lacra social y comprometiendo al Estado en la lucha por su erradicación.

Dos años después de la promulgación de la Constitución salió a la luz otro importante estudio sociológico sobre la violencia de género en el espacio público que venía a completar la Enquête nationale sur la violence à l'égard des femmes, de la que antes hemos hablado, puesto que esta última se había focalizado casi exclusivamente en el ámbito privado del hogar (violencia intrafamiliar y conyugal, fundamentalmente) descuidando, en buena medida, otras manifestaciones violentas que se producen, sobre todo, en el espacio público y profesional, en el que cada vez existe una mayor presencia de mujeres. Dicho estudio, titulado La violence fondée sur le genre dans l'espace public en Tunisie, fue publicado en 2016 en el marco institucional del Centro de Investigación, Estudios, Documentación e Información sobre la Mujer, coordinado por Slim Kallel, profesor de psicología de la Universidad de Túnez, y también en esta ocasión un organismo internacional actuaba de promotor y partenariado: ONU Mujeres. Ya en sus páginas iniciales el informe incidía en el aumento de la agresividad y de violencia de género tras las revueltas del 2010-2011, debido a la inestabilidad política y económica del país y a la crisis económica paralela (CREDIF, 2016: 13), lo cual tenía un reflejo directo en la esfera pública que debía ser analizado. Basado en una encuesta a 3.873 personas (2.873 mujeres y 957 hombres) a nivel nacional, los resultados finales revelaban datos alarmantes sobre la prevalencia de la violencia de género en el espacio público (tránsito, educativo, profesional y ocio), de tal forma que el $53,5 \%$ de las mujeres encuestadas afirmaban haber sufrido alguna forma de violencia en el espacio público durante los últimos cuatro años (2011-2015). 
(\%)
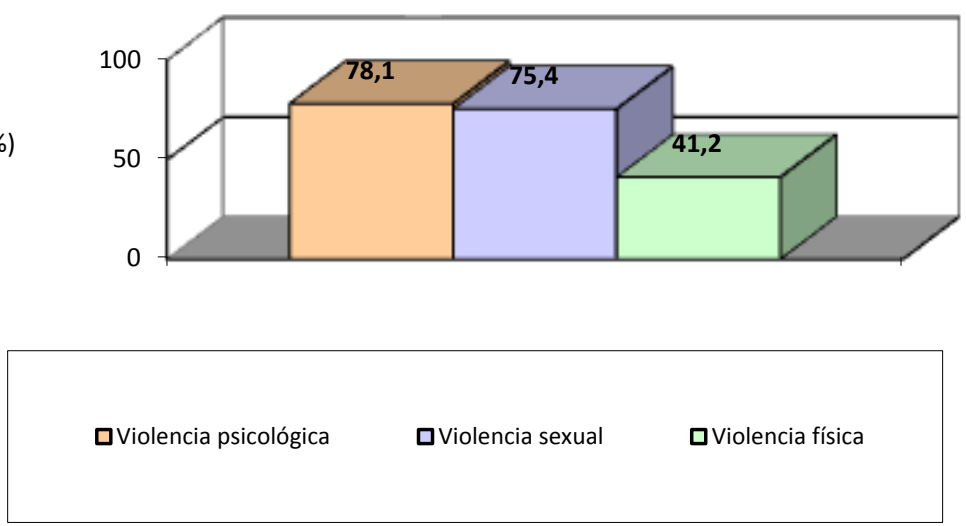

(\%)
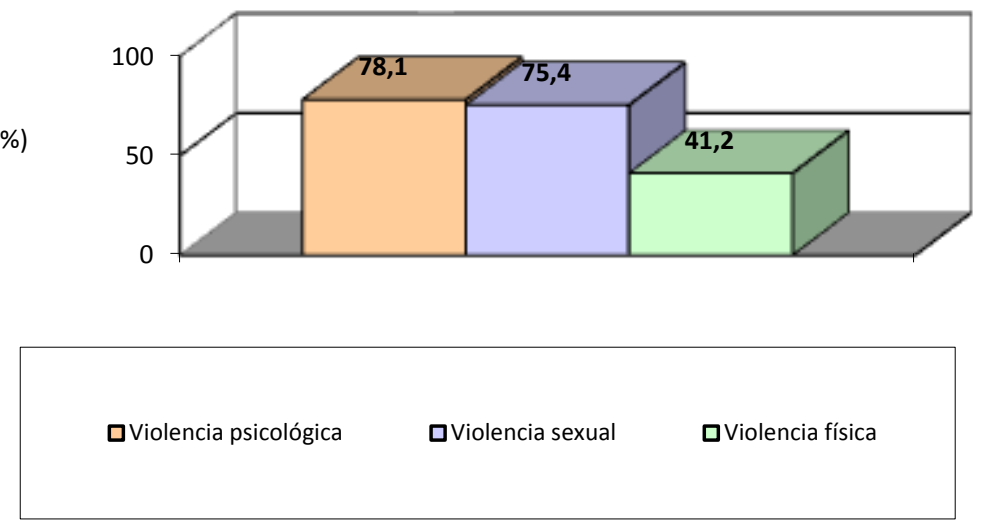

Fig. 4: Prevalencia de la violencia contra las mujeres en el espacio público, según tipos. Fuente: Realización propia a partir de los datos de CREDIF (2016: 71-72)

Como puede apreciarse en el Gráfico, la mayoría de las mujeres encuestadas (78\%) afirman haber sufrido alguna forma de violencia psicológica en el espacio público como consecuencia de ser perseguidas a pie, en moto o en coche, o de ser increpadas o insultadas. Pero un porcentaje muy similar $(75,4 \%)$ corresponde a las mujeres que dicen haber sufrido también algún tipo de violencia sexual al ser importunadas de diversas formas (propuestas, insinuaciones, gestos inapropiados, etc.) o ser tocadas o acariciadas sin su consentimiento. Incluso un $42 \%$ de las encuestadas se han visto sometidas a violencia física, sobre todo con el objetivo de arrebatarle o robarle alguna pertenencia.

Aunque todos los espacios son susceptibles de violencia contra las mujeres, los transportes públicos y el ámbito profesional se erigen como los más usuales. En este último caso, el 58,3\% de las mujeres encuestadas que trabajan afirman haber sido víctimas de algún tipo de violencia, sobre todo por discriminación o explotación económica $(39,9 \%)$, aunque también psicológica $(19,5 \%)$ y sexual $(12,9 \%)$ (CREDIF, 2016: 90$)$. 
(\%)

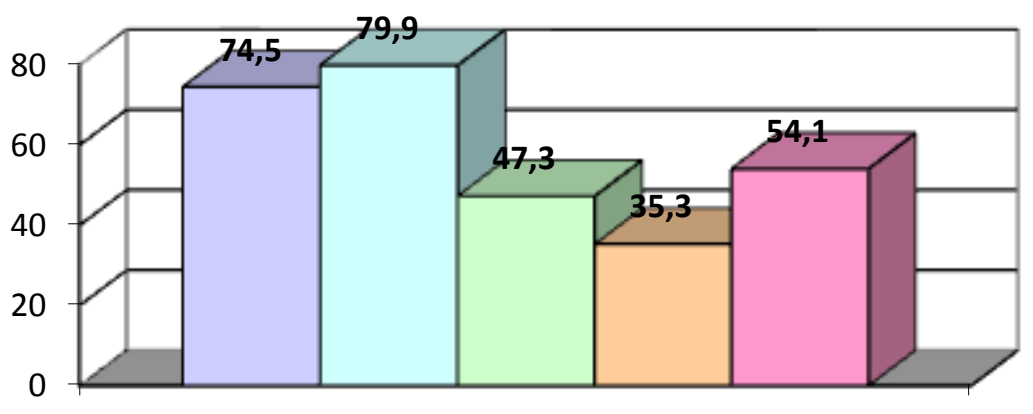

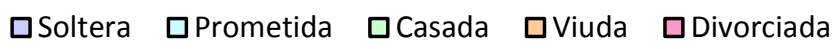

(\%)

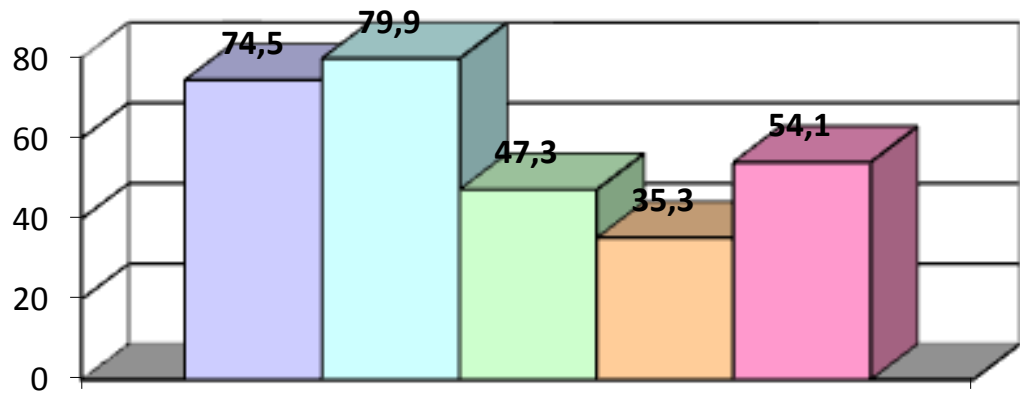

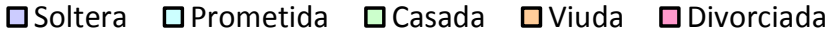

Fig. 5: Mujeres víctimas de violencia en el espacio público según estado civil. Fuente: Realización propia a partir de los datos de CREDIF (2016: 73)

Reveladores son también los datos que aporta este estudio sobre el perfil de las mujeres víctimas de violencia, de tal modo que las solteras son las que muestran porcentajes mucho más elevados que las casadas y viudas (Gráfico 5), lo cual demuestra una mayor prevalencia de la violencia entre las chicas jóvenes, ya que las sociedades patriarcales suelen mostrar una mayor dominación sobre las/los jóvenes solteras/os, mientras que el estatus de casadas y de madres repercute en un mayor reconocimiento social. Ello se encuentra corroborado, a su vez, por el hecho de que el 88,5\% de las mujeres que declaran haber sufrido actos de violencia son estudiantes y que el $81,7 \%$ buscan empleo (CREDIF, 2016: 74).

Otros muchos datos de interés muestra este estudio, imposible de abordar aquí, pero no podemos pasar por alto algunas conclusiones (CREDIF, 2016: 165-167) que inciden en la percepción del espacio público como un entorno extraño y hostil para las mujeres, que despierta en estas sentimientos de desconfianza, de exclusión y de inseguridad, de tal manera que el espacio público se erige como centro del poder simbólico de los hombres sobre el cuerpo y la autonomía personal de las mujeres, y como un lugar privilegiado para la violencia en cualquiera de sus manifestaciones. 


\section{Hacia una ley orgánica sobre violencia de género}

Ley Orgánica referente a la eliminación de la violencia contra la mujer adoptada en agosto de 2017, tuvo una compleja historia de, al menos, tres años durante los cuales el proyecto conoce una significativa evolución. Poco después de la adopción de la Constitución en 2014 y sus referencias explícitas a la eliminación de la violencia contra la mujer (el texto constitucional utiliza el singular, al-mar'a), durante el gobierno de transición de Mehdi Jomâa (enero 2014-febrero 2015) se puso en pie un primer Proyecto de ley integral, a iniciativa de la Secretaría de Estado de la Mujer, la Infancia y la Familia, que encabezaba la jurista Neila Chaabane. Con este fue designado un comité de expertos, encabezado por la prestigiosa feminista y profesora de derecho público, Sana Ben Achour, en el que participaron representantes de diversos ministerios (Mujer, Justicia, Salud, Educación, Economía, etc.) y también expertos y representantes de la sociedad civil relacionados con legislación penal y familiar, derechos humanos y violencia de género (Chaabane, 2017). Al igual que el resto de iniciativas previas, también en esta ocasión el Proyecto de ley se realizó bajo el paraguas de organismos internacionales como ONU Mujeres, Consejo de Europa, PNUD, HCDH, UNODC, etc. que aportaron el asesoramiento jurídico, las líneas generales de actuación y la experiencia previa en el tema que nos ocupa.

Con una pretensión global, el texto resultante ha sido calificado de "ambicioso" (Chaabane, 2017) o "muy ambicioso" (Bertoluzzi 2017) y abarcaba los diversos aspectos y ámbitos relacionados con las diferentes formas de la violencia de género. En este sentido, afirma Sana Ben Achour: "La ley de violencia contra las mujeres no puede reducirse a un simple código penal bis. No puede limitarse solamente a la represión, sino que debe emprender una acción interdisciplinar que tenga en cuenta, en primer lugar, los medios de prevención, sensibilización y educación para la igualdad y el respeto de la dignidad de las mujeres y, posteriormente, las instituciones e instrumentos de acompañamiento, apoyo y protección a las mujeres víctimas de violencia, así como las modalidades para la aplicación efectiva de la ley y la evaluación constante de sus resultados" (Ben Achour, 2016: 96).

De los cambios jurídicos propuestos, los más polémicos eran, sin lugar a duda, los relacionados con las prescripciones discriminatorias que aún perduran en el Código de estatuto personal (Maŷallat al-aḥwāl al-šajșiyya) en tanto en cuanto se trata de la legislación más íntimamente relacionada con la identidad nacional y cultural del sujeto histórico tunecino, no exenta de a veces de contradicciones con otras legislaciones internacionales con pretensión de universalidad (DUDH, CEDAW, etc.). A pesar de las prescripciones avanzadas que esta ley ha ido introduciendo a lo largo de los años, desde su promulgación en 1956 (Pérez Beltrán, 2011), esta norma aún conserva diversos aspectos diferenciadores entre hombres y mujeres, que desde hace décadas las asociaciones feministas reclaman su abolición, en tanto en cuanto promocionan o legitiman estructuras desiguales y diversos tipos de violencia de género. La dote es uno de ellos, puesto que, independientemente de que su valor material se haya visto reducido considerablemente, sigue siendo una condición imprescindible para el contrato matrimonial. Pero lo más grave se encuentra recogido en el artículo 13 que estipula: "El esposo no podrá obligar a la mujer a consumar el matrimonio si no paga la dote", de lo cual se puede deducir que, una vez pagada la dote, el esposo podría recurrir a la violencia sexual, e incluso a la violación, al tener el derecho legal de obligar a su esposa a mantener relaciones sexuales. Junto a ello, la cualidad del marido como jefe de familia es 
otro de los aspectos discriminatorios del Código (art. 23), puesto que establece una relación jerárquica entre jefe (marido) y subalterno (esposa), al tiempo que promociona situaciones de subordinación de las mujeres y otros aspectos relacionados con la violencia económica y la dependencia.

Otros aspectos igualmente discriminatorios del Código de estatuto personal son puestos en tela de juicio por este primer Proyecto de ley sobre violencia de género que pretende eliminar cualquier vestigio de violencia institucional y jurídica (Joumi y Kari, 2017: 15-17; Ben Achour, 2016: 36-43), entre ellos: la preponderancia del padre sobre la madre en lo relacionado con la tutela de los hijos (art. 154 ), ciertas circunstancias que arrebatan a las mujeres el derecho a la custodia de sus hijos, el desigual reparto de la herencia en función del sexo, y la eliminación de la Circular que prohíbe el matrimonio de la mujer tunecina con un hombre no musulmán .

Son también muchas las prescripciones que el Proyecto de ley integral sobre la violencia contra las mujeres pretendía eliminar o modificar del Código penal, en tanto que se trata de normas conservadoras que tienen por objetivo proteger o reproducir el orden social y las estructuras patriarcales. Uno de los aspectos más polémicos está relacionado con las distinciones que hace el Código penal sobre violación, que siempre implica violencia (art. 27), y abuso sexual sin violencia (art. 227 bis). El artículo 227 castigaba con la pena de muerte al hombre que hubiera violado a una mujer mediante el uso de la fuerza, las amenazas o las armas o a una niña menor de 10 años, mientras que fuera de estos casos la violación era castigada con cadena perpetua. En este sentido, es necesario hacer una precisión, ya que la versión árabe y oficial señalaba específicamente que se trataba de la violación de un hombre a una mujer o a una niña, mientras que en la versión francesa no señalaba esta especificidad y había dado lugar a cierta ambigüedad (Ben Achour, 2016: 66-67). Independientemente de lo injustificado que para cualquier defensor de los derechos humanos es la pena de muerte o la cadena perpetua, el artículo 227 del Código penal tenía una consideración demasiado miope y sesgada de la violación como la penetración vaginal del miembro viril mediante el uso de la fuerza, excluyendo otros casos que pudieran ocurrir de acceso carnal por vía vaginal, anal o bucal a cualquier persona de cualquier edad (mujer u hombre, niña o niño), así como la introducción de otros miembros corporales u objetos.

Más polémico aún era el artículo 227 bis referente a los abusos sexuales sin uso de la violencia, que había sido introducido en el Código penal en 1958 y modificado en 1969 y 1989, mediante el cual se establecía penas de cárcel de cinco a seis años al hombre que cometiera abusos sexuales a niñas o mujeres adultas, con lo cual no solo se excluía a niños y hombres de esta categoría de abusos sexuales, sino que establecía una sanción extremadamente dispar con respecto al caso anterior, la violación. Pero tanto o más grave aún era que dicho artículo permitía al violador eludir estas penas mediante el matrimonio con su víctima, al estipular "El matrimonio del culpable con la víctima, en los dos primeros casos previstos por este el artículo, pondrá fin al enjuiciamiento o a los efectos de la sentencia", lo cual había sido objeto de todo tipo de críticas a nivel nacional , ya que pone a la víctima en manos de su verdugo, sobre todo si tenemos en cuenta las posibles presiones familiares para subsanar lo que se considera un deshonor. En la misma línea se encontraba el artículo 239 del Código penal que permitía liberase de la cárcel al autor de secuestro de una mujer si contrae matrimonio con ella.

Sin ánimo de ser exhaustivos, finalmente otro de los grandes temas de debate se articula en torno al artículo 230 del Código Penal que condena la homosexualidad en cualquiera de sus manifestaciones al establecer que: "La sodomía (al-liwāț) o el lesbianismo (al-musāḥaqa), si no entran en ninguno de los casos previstos en los artículos precedentes, serán castigados con tres (3) años de cárcel". De nuevo hay que tomar como fuente la versión oficial en árabe, en donde se 
hace clara referencia a la homosexualidad masculina y al lesbianismo, ya que en la versión francesa solamente se menciona "la sodomie", invisibilizando la orientación femenina y creando ambigüedad jurídica. Se trata de una norma que, al igual que las anteriores, se erige en guardiana del orden social, político y moral establecido, es decir, un orden patriarcal que mantiene una concepción estrictamente binaria de la sexualidad (macho / hembra) y de la identidad de género (masculino /femenino) y que articula su estructura de poder en torno a la autoridad de los hombres sobre las mujeres, el matrimonio como único marco afectivo y sexual, y la filiación unilateral por vía patrilineal. En palabras de Meziane, "la regulación de la sexualidad masculina y femenina por la ley islámica clásica no obedece a preocupaciones morales, o a la preservación de un hipotético 'orden natura' o incluso a la perpetuación de la especie, sino a la preservación del orden público" (Meziane, 2008: 276). Y en pro de ese orden público, plagado de principios morales y prejuicios, el artículo 230 del Código Penal promueve la homofobia y criminaliza al colectivo LGTBI exclusivamente por su orientación sexual o su identidad de género, en clara contradicción con el artículo 4 de la Constitución que garantiza la igualdad ante la ley de todos los ciudadanos y las ciudadanas. Pero además de la violencia jurídica e institucional que supone esta norma, el tímido movimiento a favor de la defensa y visibilidad de LGTB que empieza a tomar forma en el país, denuncia también una serie de actos de violencia a los que se van sometidas estas personas, principalmente el denominado "test anal" con el fin de interponer la sanción estipulada en el art. 230; práctica ésta que "es reconocida por la comisión internacional de lucha contra la tortura de Naciones Unidas como un trato cruel, degradante e inhumano" (Dajm, 2014: 8).

Contrariamente a los artículos anteriormente citados del Código Penal, el artículo 230 sigue invariable tras la adopción de la Ley Orgánica referente a la eliminación de la violencia contra la mujer de 2017 y sigue siendo un tema tabú aún no asumido por el poder político. En este sentido, Anmistía Internacional señala el caso del cese del Ministro de Justicia, Mohamed Salah Ben Aissa, en octubre de 2015 como consecuencia de unas declaraciones en las que se mostraba a favor de la despenalización de la homosexualidad (Amnesty, 2015: 37).

Presentado el 12 de agosto de 2014 ante la Asamblea Nacional Constituyente, Proyecto de ley integral sobre la violencia contra las mujeres fue descartado por las fracturas ideológicas irreconciliables que despertó entre las diversas tendencias políticas e ideológicas del país, dentro de la mencionada "guerra de identidades" sobre las normas sociales que deben ser mantenidas frente a lo que se considera imposiciones hegemónicas externas, sobre todo en lo relacionado a los cambios dentro del Código de Estatuto Personal. Este acontecimiento coincidió, además, con la llegada a la presidencia del país de Béji Caïd Essebsi (31/12/2014) y de que su partido, Nidaa Tounes, creado ex profeso para las elecciones de 2012, alcanzara la mayoría de escaños parlamentarios; un partido que, a pesar de ser considerado como laico y de centroderecha (Bustos, 2014: 2; Martín, 2014), también ha sido calificado de "neo-autoritarismo y conservadurismo, acompañado de una corriente de moralización de la sociedad que no parece desagradar a Ennahda, convertido en su socio preferente" (Mohsen Finan, 2016). Tras más de un año de impasse, el Proyecto de ley inicial fue revisado y reformado en 2016, bajo la tutela de la nueva Ministra de la Mujer, la Familia y la Infancia, Samira Merai, y actual Ministra de Salud que, debido a sus planteamiento ideológicos (ha sido considerada poco proclive al feminismo ) o a la praxis política (coalición con Ennahda), optó por una propuesta mucho más moderada en la que se suprimieron todos los planteamientos que sobrepasaban las "líneas rojas" de las identidades 
nacionales: el Código de Estatuto Personal y la despenalización de la homosexualidad y del adulterio, entre otras cuestiones.

Finalmente, esta nueva versión, que ahora recibía el nombre de Proyecto de Ley Orgánica referente a la eliminación de la violencia contra la mujer, fue adoptada el 13 de julio de 2017 por el Consejo de Ministros y aprobada el día 26 de julio de ese mismo año por la Asamblea de Representantes del Pueblo, contando con la unanimidad de los miembros asistentes: 146 votos a favor y 0 abstenciones (Youssfi, 2017).

\section{Ley Orgánica 58/2017, del 11 de agosto, referente a la eliminación de la violencia contra la mujer}

Publicada en el Boletín Oficial el día 11 de agosto de 2017, la Ley Orgánica 58/2017 referente a la eliminación de la violencia contra la mujer, que ha entrado en vigor seis meses después (art. 44), el 11 de febrero de 2018, es un texto legislativo que plasma un determinado discurso y construye una determinada narrativa (oficial) de la violencia de género, de tal manera que, como dijimos en la hipótesis de parida, los mecanismos ideológicos de la subalternidad hacen que dicho texto establezca ciertos límites para seguir conservando los valores ideológicos y culturales considerados como integrantes de la nacionalidad tunecina. Consta de 44 artículos repartidos en 5 grandes títulos, el primero de los cuales marca los objetivos de la ley, a saber, "eliminar todas las formas de violencia contra la mujer fundadas sobre la discriminación de los sexos a fin de asegurar la igualdad y el respeto de la dignidad humana" (art. 1). Además de ello, en este primer apartado, un extenso artículo 3 define el concepto de violencia contra "la mujer" como toda agresión basada en la discriminación sexual, que causa prejuicio, sufrimiento o lesión en las víctimas (mujeres y niños), distinguiendo siete tipos de violencia: física, moral, sexual, política, económica, discriminación de las mujeres y situación de vulnerabilidad. Considerando la violencia contra las mujeres como una violación de los derechos humanos (art. 4, primer párrafo), el Estado se compromete a "hacerse cargo de la mujer víctima de violencia y de los niños que residan con ella" (art. 4, primer párrafo) y a desarrollar políticas, planes estratégicos y programas de diverso tipo a fin de "eliminar todas las formas de violencia contra la mujer en el entorno familiar, social, educativo, la formación profesional, la salud, la cultura, los deportes y los medios de comunicación" (art. 4).

Una vez definidos los conceptos, la Ley Orgánica 58/2017 articula su contenido en tres ejes principales: la prevención, la protección y el enjuiciamiento.

La prevención: Mediante lo implicación de diversos ministerios (enseñanza, salud, justicia, juventud, mujer, asuntos religiosos), la Ley señala una serie de principios generales, basados en la educación, con el fin de prevenir la violencia, sin especificar demasiado su puesta en práctica ni hacer referencia alguna a los recursos empleados en ello. De este modo, el Estado se compromete a llevar a cabo programas didácticos, educativos y culturales, basados en los valores de los derechos humanos, que transmitan principios de igualdad y no-discriminación, (art. 7). En este sentido, la Ley hace una referencia expresa a los medios de comunicación (art. 11), los cuales deben implicarse en la divulgación de principios igualitarios, en la sensibilización sobre las consecuencias de este grave problema social y en la exclusión de cualquier tipo de publicidad estereotipada, sexista o perjudicial para las mujeres.

Finalmente, como medida de prevención, la Ley prevé en su artículo 40 la creación de un "Observatorio nacional de contra la violencia contra la mujer", con las siguientes funciones: 
detectar casos de violencia contra las mujeres, controlar la aplicación de la legislación y las políticas evaluando su efectividad y eficiencia, llevar a cabo investigaciones científicas y de campo en este ámbito, definir los principios rectores para la eliminación de este tipo violencia de acuerdo a la ley, garantizar la cooperación y la coordinación con la sociedad civil, y asesorar sobre los programas de formación en violencia de género.

La protección: Este apartado empieza, igualmente, enumerando una serie de derechos generales sobre la protección de las víctimas, como son: la protección jurídica, el acceso a la información, la reparación económica, el seguimiento sanitario y psicológico, y el realojamiento inmediato de las víctimas y sus hijos "en los límites los medios disponibles". De nuevo, se evita cualquier referencia a los recursos. Dentro de este apartado, quizás lo más novedoso es el contenido del artículo 14, el cual obliga a toda persona, incluyendo a las que están sujetas a secreto profesional, a "notificar a las autoridades competentes cualquier caso de violencia en el sentido de la esta Ley, tan pronto como tenga conocimiento de ella, la haya observado o haya notado sus efectos", advirtiendo además que no se puede desvelar la identidad de la persona que ha alertado del problema sin su consentimiento (art. 14 último párrafo).

Mediante la creación de unidades especializada dentro de los cuerpos de seguridad del Estado que, además, deben estar formadas en violencia de género e incluir obligatoriamente a mujeres entre sus miembros (art. 24), la Ley establece una serie de medidas de protección, como: trasladar a la víctima y a sus hijos a lugares seguros o a centros hospitalarios, en caso de necesidad, y establecer medidas para alejar al acusado del domicilio de la víctima o prohibirle acercarse al lugar en donde esta se encuentre, en el supuesto de peligro manifiesto.

Finalmente, el artículo 33 enumera las posibles medidas de protección que puede tomar el juez de familia, dependiendo de los casos particulares, tales como: prohibir al demandado ponerse en contacto con la mujer y sus hijos, obligar al acusado a abandonar el hogar familiar, prohibir al demandado el uso de la propiedad privada de la víctima o sus hijos, permitir a la víctima recuperar sus posesiones y enseres personales, determinar la pensión compensatoria y de alimentos, etc.

El enjuiciamiento. Se trata de la parte más extensa de la Ley que tiene por objetivo modificar, sustituir o introducir nuevos artículos del Código penal, algunos de los cuales ya hemos citado anteriormente.

Sin ánimo de ser exhaustivos, las principales modificaciones legislativas que introduce el Título tercero, denominado "De los delitos de violencia contra la mujer" son los siguientes:

- Se hace una nueva definición de violación (igtișāb) en la que se contempla a la víctima de ambos sexos al establecer que: "Se considera violación todo acto de penetración sexual, cualquiera sea su naturaleza y los medios usados, cometidos contra una persona de sexo femenino o masculino sin su consentimiento" (art. 227 nuevo). La pena de muerte que aparecía en principio es ahora eliminada, mientras que se sigue conservando la cadena perpetua para los supuestos de amenazas o uso de la fuerza, menores de edad, abuso de la autoridad y vulnerabilidad de la víctima. Igualmente se incluye en esta categoría una novedad importante que, hasta ahora, no contemplaba el Código penal por el tabú que ello comporta: el incesto (sifāḥ alqurbà) cometido por cualquier familiar (ascendientes, hermanos, cónyuges de alguno de los padres, sobrinos, etc.) con menores de edad. En el resto de casos, la pena contemplada por el delito de violación es de 20 años de cárcel. 
- $\quad$ Además de desaparecer del nuevo artículo 227 bis la posibilidad de eludir la pena de cárcel del agresor mediante el matrimonio con la víctima, que tanta polémica había generado durante décadas, este artículo incluye también a los varones dentro de la consideración de abusos sexuales, al establecer "una pena de cinco (5) años a quien mantenga de forma voluntaria relaciones sexuales con un niño, sea de sexo femenino o masculino, cuya edad sea mayor de dieciséis (16) años y menor de dieciocho (18), con su consentimiento". La pena se dobla en algunos casos relacionados, sobre todo, con situaciones de autoridad sobre la víctima o situación de vulnerabilidad de esta.

- En el caso de violencia física, el nuevo artículo 228 aumenta considerablemente las casuísticas, introduciendo como novedad la cadena perpetua si la víctima es un niño, el autor es un ascendiente, descendiente o tiene autoridad sobre esta, o si el autor es uno de los cónyuges, excónyuges, novios o exnovios (estas últimas categorías tampoco estaban contempladas anteriormente). Idéntica pena si la víctima se encuentra en una situación de vulnerabilidad, si hay premeditación, amenazas o uso de armas, etc.

- Mediante el nuevo artículo 226 ter, se eleva a dos años la pena de cárcel y a 5.000 dinares la multa por el delito de acoso sexual (al-taḥarruš al-ŷinsī) (anteriormente era un año y 3.000 dinares), al tiempo que se define dicho delito como "toda agresión cometida por terceros mediante actos, gestos o palabras con connotaciones sexuales que atenten a su dignidad o afecten a su pudor, y ello con el propósito de lograr que se someta a los deseos sexuales del agresor o de otros, o ejerciendo sobre ella una presión peligrosa que puede debilitar su capacidad para resistirse a ello". Como en los casos anteriores, la pena se puede ver incrementada al doble si la víctima es un niño, si el autor es un ascendiente, descendiente o tiene autoridad sobre esta, o en situación de vulnerabilidad.

Se introduce un párrafo nuevo en el artículo 224 y un nuevo artículo (224 bis) con el objetivo de criminalizar la violencia conyugal, asimilando las penas a los maltratos cometidos contra los hijos (art. 224). En cuanto al nuevo artículo introducido, establece una pena de cárcel de seis meses a un año de prisión y una multa de 1.000 dinares al autor de violencia física y psicológica contra su cónyuge, excónyuge, pareja o expareja de forma repetida.

- $\quad$ Otras novedades que introduce la Ley Orgánica 58/2017, ya fuera del Código penal, están relacionadas con ciertas formas de agresión verbal o gestual a las mujeres en el espacio público (art. 17), la violencia política (art. 18), la discriminación económica basada en el sexo (art. 19), el trabajo infantil (art. 20) y la privación o restricción de derechos de la víctima (art. 21).

\section{¿Éxito o fracaso? Debates sobre la Ley orgánica 58/2017}

Los debates que se plantean después de la promulgación de la Ley Orgánica 58/2017 referente a la eliminación de la violencia contra la mujer apenas si experimentan cambio respecto a los planteados durante sus años de redacción como Proyecto de ley y oscilan desde los planteamientos más optimistas que consideran que se trata de una conquista de gran relevancia para las mujeres y el país en general, hasta los que consideran que debe ser reenviado al parlamento para una nueva propuesta legislativa.

En el primer caso encontramos, en primer lugar, la postura oficial del gobierno, cuya representante más implicada en la adopción de la Ley orgánica, la Ministra de la Mujer, la Familia y la Infancia del momento, Naziha Laabidi declaraba: "es un momento conmovedor y estamos 
orgullosos en Túnez de haber podido unirnos en torno a un proyecto histórico" (AFP, 2017), para concluir afirmando "es la apoteosis después del Código de estatuto personal iniciado en 1959" (ONU Femmes, 2017). En la misma línea, Bochra Belhaj Hmida, diputada y miembro del Comité ejecutivo del partido presidencial, Nidaa Tounes, señalaba que la ley "tiende a poner fin a todas las formas de violencia contra las mujeres", para a continuación incidir en el poso filosófico de la norma que, según la diputada, es que "esta violencia ya no es un asunto privado, sino que ahora es una cuestión que concierne al Estado; la prueba de ello es que la retirada de la demanda ya no detiene el enjuiciamiento" (AFP, 2017b). En este caso, las apreciaciones van siempre encaminadas a la lucha emprendida desde hace años y en los logros que la ley introduce obviando posibles lagunas jurídicas o posibles obstáculos económicos o institucionales.

En general las posturas que muestran una defensa más apasionada de la Ley orgánica 58/2017 beben del referente cultural y conceptual que desde hace décadas viene defendiendo el movimiento feminista global y las instituciones internacionales más relacionadas con este tema: el concepto de género como construcción discursiva y cultural, partiendo de una visión globalizante de lo político (Paterman, 1996) que abarca también al matrimonio, la familia o la educación de los hijos. Esta es la postura de la sociedad civil tunecina que ha estado más comprometida con la adopción de esta Ley, sobre todo las asociaciones feministas, que también la recibieron con gran optimismo, incidiendo sobre todo en los avances que suponía esta norma y sin apenas evidenciar las importantes propuestas que habían quedado en el tintero durante los años de su elaboración como Proyecto de Ley, especialmente las relacionadas con la eliminación de las prescripciones discriminatorias del Código de estatuto personal o la abrogación de los artículos del Código penal que aún hoy día criminalizan la homosexualidad, el adulterio o la prostitución. De esta forma, el movimiento denominado "Coalición de la sociedad civil para la adopción de la ley relativa a la eliminación de la violencia contra las mujeres", en el que participaban las asociaciones de mujeres más destacadas del país (ATFD y AFTURD, entre otras) emitieron un informe cuyas primeras palabras ya denotan la sensación de éxito "El 26 de julio de 2017 marca una nueva página de la historia de Túnez", para proseguir afirmando: "las activistas y las organizaciones feministas de la Coalición se sienten orgullosas y agradecidos (as) a todos los que y las que han apoyado este combate"

Los organismos internacionales que, como dijimos anteriormente, se implicaron desde un principio en la adopción de la Ley, participan igualmente de esta visión optimista, como es el caso de ONU Mujeres que afirma "esta culminación es el resultado de varios años de esfuerzos por parte de una sociedad civil altamente comprometida y de las instituciones nacionales, contando con una fructífera colaboración de varias organizaciones internacionales, entre ellas ONU Mujeres", para proseguir con la siguiente afirmación que, hoy día, resulta cuando menos discutible: "antes de la aprobación de esta Ley, el Código del Estatuto Personal de 1956 era la única legislación progresiva de este tipo" (ONU Femmes, 2017).

También es cierto que otros organismos, como Human Rights Watch, aun reconociendo las aportaciones de esta legislación, inciden en la necesidad de que ello no se quede en una filosofía teórica o en una simple propuesta estratégica, sino que las autoridades deben garantizar la existencia de "fondos suficientes y voluntad política indispensable para que le Ley entre en pleno vigor y que sean eliminadas las discriminaciones hacia las mujeres" (Youssfi, 2017). Y en la misma línea encontramos las declaraciones de la red EuroMed que, a pesar de señalar los significativos avances de la legislación, no por ello deja de evidenciar sus lagunas, de las que señala dos tipos 
(EuroMed, 2017). En primer lugar, desde el punto de vista jurídico, la criminalización de las relaciones sexuales entre menores de 16 a 18 años y la falta de referencias expresas a la violación conyugal. En segundo lugar y, quizás el más importante, EuroMed incide también la falta de previsión económica y en la ausencia de presupuestos destinados a su aplicación, señalando: "desde la adopción de esta ley hasta la fecha no se ha promulgado ningún texto de aplicación; el sistema de protección (asistencia telefónica, centros de acogida, apoyo psicológico, etc.) previsto por la Ley todavía no está en vigencia, el presupuesto no ha sido definido y no se ha establecido un cronograma para su implementación".

Esta línea de pensamiento más moderada se encuentra también presente en el debate sociopolítico interno de Túnez, como el que mantiene Nadia Chaabane, antigua miembro de la Asamblea Constituyente, quien afirma: "esta ley es un buen comienzo para la consagración del artículo 46 de la Constitución, pero aún debe fortalecerse para erradicar de forma efectiva todas las violencias contra las mujeres. Los textos tunecinos aún contienen muchos artículos y disposiciones a los que se le deben quitar el polvo, porque están retrasados con respecto a la evolución de la sociedad tunecina y también se han vuelto anticonstitucionales, violando los artículos 21 y 46 de la Constitución", señalando a continuación las prescripciones discriminatorias del Código de estatuto personal y los aspectos menos desarrollados de la propia Ley orgánica 58/2017 (Chaabane, 2017).

En cuanto a las posturas opuestas a la Ley, surgen principalmente de las tendencias ideológicas que vinculan la acción política islámica con la acción nacional, a través de una lectura histórica de la identidad y la cultura islámica del país, en la que "la mujer" y la familia se sitúan como base social e institucional frente a la concepción secularista occidental y al enfoque de género que suponen, según estos, un peligro para el orden social del país y su identidad religiosa (Pérez y Macías, 2017). En buena medida, son planteamientos contrahegemónicos de la subalternidad en tanto que se trata de disidencias individuales o colectivas, el "arte de resistencia de los dominados" dirá Scott (2000: 227-237), frente a un centro ideológico omnipresente (poscolonial) del que resulta difícil escapar.

De este modo, Monia Ibrahim, parlamentaria de Ennahda, que años antes había defendido la complementariedad en la Constitución, se erige como acérrima opositora a la Ley orgánica, bajo la argumentación de que se trata de una norma incompatible con los valores de la familia musulmana, que "golpeará el corazón de la religión islámica y manchará la identidad misma de la sociedad tunecina" (Khouili y Levine-Spound, 2017), mientras que el también diputado de Ennahda, Noureddine Bhiri, se mostraba partidario de bajar a los 13 años la edad de mayoría sexual (Dahmani, 2017). No obstante, la versión oficial del Partido Ennahda es bastante más moderada optando siempre por el voto y consenso, de tal forma que aunque el partido muestre su disconformidad con ciertas cuestiones de la Ley, se muestra partidario en su conjunto ya que, en palabras de Rachid Ghannouchi, "respeta el marco referencial del Islam que siempre llamó a tratar bien a la mujer. Por este motivo respetamos todos los documentos que estipulan el respeto de los derechos de las mujeres, empezando por el Código de Estatus Personal".

Ennahda no es el único movimiento cuyos militantes manifiestan hostilidad a esta legislación. En la misma línea contrahegemónica de la subalternidad podríamos calificar las declaraciones de Salem Labiadh, diputado del Movimiento Popular (en teoría, un partido socialista y nacionalista árabe), el cual considera que la ley contra la violencia contra las mujeres "podría instaurar un feminismo radical, destruir los pilares de la familia y legalizar la homosexualidad". 
Pero de las posturas contrarias a la Ley, quizás la más interesante por sus planteamientos sea la del sociólogo, antiguo diplomático y activo bloguero Fathat Othman, quien propone reenviar cuanto antes al parlamento la Ley orgánica 58/2017, ya que lejos de un pretendido marco integral, la Ley va solo al detalle, modificando algunos artículos muy particulares que constituyen la punta de iceberg de un pensamiento profundamente anclado que discrimina a las mujeres y que se encuentra legitimado ideológicamente en las normas que fueron excluidas del primitivo Proyecto de ley, es decir, los planteamientos discriminatorios del Código de Estatuto Personal y otras cuestiones relacionadas con las orientaciones sexuales y el derecho a la diferencia: "por lo tanto, es a nivel mental donde hay que abordar este problema y esta violencia que anida en las cabezas, no necesariamente del pueblo, que está sofocado y apenas sobrevive en un ambiente represivo, sino de las élites que la gobiernan con leyes liberticidas", porque "cuando una ley contra la violencia descuida lo esencial en pro de lo accesorio, olvidando la causa para concentrarse en el efecto, es solo una nueva violencia" (Othman, 2017).

Además de sus planteamientos contra los esquemas mentales que legitiman la violencia, resultan interesantes sus apreciaciones sobre los principales responsables de esta situación, las élites, pero responsabilizando sobre todo a las élites laicas, incluyendo a las asociaciones feministas, que bien por pragmatismo o imposición de organismos internacionales, han terminado por aceptar lo accesorio y puntual olvidando lo realmente importante, mientras que, por el contrario, "los religiosos tunecinos han demostrado mayo capacidad de evolucionar" (Othman, 2017), incluso sobre asuntos como el consumo de alcohol y de cannabis o la lucha contra la homofobia.

Quizás como práctica contrahegemónica de disidencia o como vivencia personal de subordinación, el bloguero concluye: "en verdad se trata solo de leyes ideadas por ONG occidentales, desconectadas de la realidad de nuestro país y talladas a medida de la realidad occidental". Y como ejemplo chocante: "este es el caso de la violencia y del acoso a las mujeres que solo tienen sentido en un país donde ya existe la igualdad real, que es el caso de Occidente, pero no en Túnez. ¿Cómo puede pretender lidiar contra el acoso y las violencias menores, cuando la mayor violencia, absoluta incluso, se descuida e incluso se confirma, teniendo la precaución de no hablar de ella?" (Othman, 2017).

\section{A modo de conclusión}

Desde su misma denominación, la Ley Orgánica 58/2017 referente a la eliminación de la violencia contra la mujer refleja las relaciones de poder entre un centro ideológico dominante que promueve ciertos recursos gramaticales (el término género, mujeres en plural) y las estrategias contrahegemónicas de disidencia o resistencia a dichas narrativas eurocéntricas.

El debate sobre la violencia de género (todos los géneros) responde a una realidad social altamente preocupante, como bien han demostrado los estudios sociológicos sobre la prevalencia de este tipo de violencia en el espacio privado (Enquête nationale sur la violence à l'égard des femmes en Tunisie, 2010), sobre todo la violencia intrafamiliar de tipo conyugal, y la violencia en el espacio público (La violence fondée sur le genre dans l'espace public en Tunisie, 2016), principalmente la violencia psicológica que sufren las mujeres jóvenes. Cierto es también que la violencia sufrida por otros colectivos (gays, lesbianas, transgénero, trabajadoras/es del sexo...) no 
ha sido tan estudiado ni tan asumido por la sociedad civil, ni mucho menos por las instituciones del Estado que sigue obcecado en negar esta realidad. Los debates sobre violencia contra las mujeres, que en principio no sobrepasaban los límenes de contadas asociaciones feministas, lograron con el tiempo traspasar estas fronteras para ser asumidos, en buena medida, por el Estado a través de la puesta en marcha de distintas instituciones y planes estratégicos, la mayoría de estos bajo la tutela de instituciones extranjeras u organismos internacionales, despertando la susceptibilidad de grupos e individuos que, como práctica contrahegemónica, critican el carácter impositivo occidental, siempre interesado, y propone, como contrapartida, la relectura/adaptación de ciertas especificidades culturales, históricas y nacionales.

En buena medida, la evolución experimentada por el Proyecto de ley sobre violencia contra "las mujeres" de 2014 hasta llegar al texto que se presentó ante la Asamblea de Representantes del Pueblo en 2017, refleja bien las dinámicas ideológicas de la sociedad tunecina en su búsqueda por traducir e interpretar las narrativas globalizantes eurocéntrica, que constituyen la hipótesis de este trabajo. Si el Proyecto de ley de 2014, realizado bajo la égida de organismos internacionales, proponía reformas integrales de gran calado, proponiendo la modificación de las prescripciones discriminatorias del Código de Estatuto Personal y del Código penal, el texto resultante hizo oídos sordos a la primera legislación señalada, en donde se fundamenta los valores ideológicos y culturales considerados como parte intrínseca de la nacionalidad y la cultura tunecinas. De este modo, aunque la Ley Orgánica 58/2017, que entró en vigor en febrero de 2018, introduce cuestiones importantes sobre la prevención, la protección y el enjuiciamiento, como han reseñado sus más apasionados/as defensores/as, sin embargo mantiene una visión miope y pragmática sobre la violencia de género, puesto que no ataca los fundamentos ideológicos que legitiman esta violencia. También es cierto que, incluso así, otras líneas de debate más disidentes rechazan en su totalidad la ley adoptada en base a un orden social del país y una identidad religiosa como fundamentos contrahegemónicos. Lo cierto es que nuestra hipótesis de partida parece confirmarse, puesto que los debates internos sobre los mecanismos ideológicos de la subalternidad han provocado que el texto normativo ponga los límites para evitar cualquier alteración de los valores ideológicos y culturales considerados como integrantes de la nacionalidad tunecina.

Lo preocupante de ello es que esta dinámicas entre un centro hegemónico dominante y una periferia que busca nichos de autonomía cultural e ideológica contribuyen a perpetuar situaciones de injusticia, de angustia y de sufrimiento en personas de cualquier orientación sexual y/o de cualquier género que, como seres humanos, tienen "todos los derechos y libertades proclamados en esta Declaración, sin distinción alguna de raza, color, sexo, idioma, religión, opinión política o de cualquier otra índole, origen nacional o social, posición económica, nacimiento o cualquier otra condición" (art. 2 DUDH), y como ciudadanos/as tunecinos "son iguales ante la ley en derechos y deberes. Son iguales ante la ley sin discriminación" (art. 21 CT).

\section{Bibliografía}

AFP (2017a): "La Tunisie vote une loi pour `en finir avec les violences contre la femme'”, L'Express, disponible en : https://www.lexpress.fr/actualite/monde/afrique/la-tunisie-vote-une-loi-pour-enfinir-avec-les-violences-contre-la-femme 1931055.html [consulta: 31 de julio de 2018].

APF (2017b): "La Tunisie vote une loi contre les violences faites aux femmes", Le Figaro, disponible en: $\quad$ http://www.lefigaro.fr/flash-actu/2017/07/26/97001-20170726FILWWW00392-la-tunisievote-une-loi-contre-les-violences-faites-aux-femmes.php [consulta: 31 de julio de 2018]. 
AFP (2018): "En Tunisie, un projet de loi pionnier pour l'égalité homme-femme dans I'héritage ", Le Point International, disponible en : http://www.lepoint.fr/monde/en-tunisie-un-projet-de-loipionnier-pour-l-egalite-homme-femme-dans-l-heritage-13-08-2018-2243389 24.php [consulta: 30 de julio de 2018].

AMNESTY INTERNATIONAL (2015): Les victimes accusées. Violences sexuelles et liées au genre en Tunisie, disponible https://www.amnesty.org/download/Documents/MDE3028142015FRENCH.PDF [consulta: 28 de julio de 2018].

AMORÓS, Celia y DE MIGUEL, Ana (2005): Teoría feminista. De la ilustración a la globalización, Madrid, Minerva.

CHERIF, Khadija (coord.) (2008): Femmes et République : un combat pour l'égalité et la démocratie, Túnez, ATFD.

BADRAN, Margot (2012): Feminismo en el Islam, Madrid, Cátedra.

bell hooks et alii (2004): Otras inapropiables Feminismos desde las fronteras, Madrid, Traficantes de Sueños.

BEN ACHOUR, Sana (2016): Violence à l'égard des femmes : les lois du genre, Túnez, Le Réseau Euro-Méditerranéen des Droits de l'Homme.

BERTOLUZZI, Giulia: "La violence contre les femmes en débat en Tunisie", disponible en: https://orientxxi.info/magazine/la-violence-contre-les-femmes-en-debat-en-tunisie, 1853

[consulta: 27 de julio de 2018].

BHABHA, Homi K. (2013): Nación y narración. Entre la ilusión de una identidad y las diferencias culturales, Madrid, Siglo XXI.

BOBIN, Frédirik (2017): "Les Tunisiennes musulmanes pourront dorénavant se marier avec des non-musulmans", Le Monde, disponible en :

https://www.lemonde.fr/afrique/article/2017/09/15/la-tunisie-met-fin-a-l-interdiction-du-

mariage-avec-des-non-musulmans 5185969 3212.html [consulta: 31 de julio de 2018].

BUSTOS, Rafael (2014): "Túnez. Elecciones legislativas, 26 de octubre de 2014", disponible en: http://www.opemam.org/sites/default/files/TUNEZ\%20An\%C3\%A1lisis\%20post\%20Bustos\%20201 4 0.pdf [consulta: 29 de julio de 2018].

BUTLER, Judith (1990): Gender Trouble. Feminism and the Subversion of Identity, New York, Routledge.

CHAABANE, Nadia (2017): "Loi intégrale de lutte contre les violences faites aux femmes: Un bon début dans la consécration de l'article 46 de la constitution", disponible en: https://www.huffpostmaghreb.com/nadia-chaabane/un-bon-debut-dans-la-consecration-de-

larticle-46-de-la-constitution b 17601172.html?utm hp ref=maghreb [consulta: 28 de julio de 2018].

CREDIF (2016): La violence fondée sur le genre dans l'espace public en Tunisie, Túnez, Centre de Recherches, d'Études, de Documentation et d'Information sur la Femme / ONU Femmes.

DABASHI, Hamid (2009): Post-Orientalism: Knowledge and Power in a Time of Terror, Piscataway, Transaction.

DABASHI, Hamid (2012): The Arab Spring: The End of Postcolonialism, New York, Zed Books.

DAHMANI, Frida (2017): "Tunisie : la loi sur l'élimination des violences faites aux femmes adoptée au Parlement", Jeune Afrique, disponible en: http://www.jeuneafrique.com/461141/politique/lestunisiennes-matent-la-violence-par-la-loi// [consulta: 31 de julio de 2018]. 
DAJM (2014): Rapport-UPR-LGBTQI-Tunisie, disponible en: https://tn.boell.org/sites/default/files/rapport-upr-Igbtai-tunisie.pdf [consulta: 26 de julio de 2018].

DE LUJÁN PIATTI, María (2013): Violencia contra las mujeres y alguien más..., Valencia, Universidad de Valencia (Tesis Doctoral).

EMAKUNDE (2009): Violencia contra las mujeres, Instituto Vasco de la Mujer, disponible en: http://www.euskadi.eus/contenidos/informacion/viol informe/es emakunde/adjuntos/informe violencia marzo 2009.pdf [consulta: 30 de julio de 2018].

EUROMED (2017): "Lacunes de la loi intégrale en Tunisie", disponible en: https://euromedrights.org/fr/publication/lacunes-de-la-loi-integrale-en-tunisie/ [consulta: 31 de julio de 2018].

GANMI, Azza (1993): Le mouvement féministe tunisien : témoignage sur l'autonomie et la plurallité du mouvement des femmes (1979-1989), Túnez, Chama Edition.

GHACHEM, Mourad y AMMAR, Sofien (2006) : La stratégie de plaidoyer autour de l'adoption de la loi organique relative à l'élimination de la violence à l'égard de la femme, et la révision des dispositions législatives discriminatoires, Túnez, Ministère de la Femme et la Famille, United Nations Population Fund.

GUHA, Ranajit (2002): Las voces de la historia y otros estudios subalternos, Barcelona, Crítica.

HERNÁNDEZ JUSTO, Tatiana (2016): "El papel del Islam en el pensamiento feminista de Tāhar alHaddād", Feminismo/s, no 28, pp. 133-146. http://dx.doi.org/10.14198/fem.2016.28.05

HENRY, Jean Robert (1988): "Imaginaire juridique", en André-Jean Arnaud (dir.) : Dictionnaire encyclopédique de théorie et de sociologie du droit, París, Librairie Générale de Droit et de Jurisprudence et Story Scientia, pp. 180-182.

JOUINI, Hamila y KARI, Monia (2017): Guide de cent mesures pour l'éradication des violences à l'encontre des femmes et des petites filles, Túnez, Association Tunisienne des Femmes Démocrates.

KHOUILI, Ramy y LEVINE-SPOUND, Daniel (2017): “La loi contre les violences, une nouvelle victoire pour les femmes tunisiennes", disponible en: http://www.middleeasteye.net/fr/opinions/la-loicontre-les-violences-une-nouvelle-victoire-pour-les-femmes-tunisiennes-1819380313 [consulta: 31 de julio de 2018].

MACÍAS AMORETTI, Juan Antonio (2018): "El post-orientalismo como marco teórico: posibilidades y limitaciones desde el análisis del discurso intelectual magrebi”, en GÓMEZ GARCíA, Luz (ed.), Continuar, romper, reelaborar: la tradición islámica en el siglo XXI, Madrid, Ediciones del Oriente y del Mediterráneo (en prensa).

MAHFOUDH, Dorra (2014): “Le Collectif Maghreb-Égalité 95: pour un mouvement féministe maghrébin”, Nouvelles Questions Féministes, no 33, 2, p. 132-135. DOI: https://doi.org/10.3917/nqf.332.0132

MAQUEDA, María Luisa (2006): "La violencia de género. Entre el concepto jurídico y la realidad social", Revista Electrónica de Ciencia Penal y Criminología, disponible en: http://criminet.ugr.es/recpc/08/recpc08-02.pdf [consulta: 31 de julio de 2018].

MARTíN, Iván (2014): “Túnez tras las elecciones presidenciales: tres logros, dos incertidumbres y tres retos", CIDOB, disponible en: http://ibdigital.uib.es/greenstone/collect/cd2/archives/cidob004/8.dir/cidob0048.pdf [consulta: 29 de julio de 2018].

MARTÍNEZ FUENTES, Guadalupe (2011): “La transición democrática post-benalista: procedimiento y alcance del cambio político en Túnez", Revista Jurídica de la Universidad Autónoma de Madrid, no 23, pp. 119-134.

MARTÍNEZ FUENTES, Guadalupe (2013): “Ennahdha ante el cambio político en Túnez: 2011-2013”, Revista de Estudios Internacionales Mediterráneos, no 15, pp. 31-53. 
MEZIANE, Mohamed (2008): "Sodomie et masculinité chez les juristes musulmans du IXe au Xie siècle ", Arabica, no 55, pp. 276-306. DOI : https://doi.org/10.1163/157005808X310651

MONSEN-FINAN, Khadija (2016): "Les espoirs déçus de la révolution tunisienne. Sur fond de complicité entre Nidaa Tounès et Ennahda", Orient XXI, disponible en: https://orientxxi.info/magazine/les-espoirs-decus-de-la-revolution-tunisienne,1164 [consulta: 23 de julio de 2018].

ONFP (2010): Enquête nationale sur la violence à l'égard des femmes en Tunisie. Rapport d'enquête, Túnez: I'Office National de la Famille et de la Population, Agencia Española de Cooperación Internacional, disponible en : http://www.medcities.org/documents/10192/54940/Enqu\%C3\%AAte+Nationale+Violence+envers +les+femmes-+Tunisie+2010.pdf [consulta:24 de julio de 2018].

ONU Femmes (2017): "La Tunisie adopte une loi historique pour mettre fin à la violence envers les femmes", disponible en : http://maghreb.unwomen.org/fr/actualitesevenements/actualites/2017/07/vote-loi-contre-violences-tunisie [consulta: 19 de julio de 2018]. OTHMAN, Fathat (2017): "Pour un renvoi au parlement de la loi sur les violences aux femmes", disponible en: https://www.huffpostmaghreb.com/farhat-othman/pour-un-renvoi-auparleme b 17636354.html [consulta: 20 de julio de 2018].

PATEMAN, Carole (1996): “Críticas feministas a la dicotomía publico/privado", en CASTELLS, Carme (ed.), Perspectivas feministas en teoría política, Barcelona, Paidós, 1996, pp. 31-52.

PÉREZ BELTRÁN, Carmelo (2011): “Una ley en constante evolución: el derecho de familia en Túnez desde la independencia a la actualidad", Miscelánea de Estudios Árabes y Hebraicos. Sección Árabe-Islam, no 60, pp. 235-254.

PÉREZ BELTRÁN, Carmelo y MACÍAS AMORETTI, Juan Antonio (2017): “La construcción histórica de la hegemonía ideológica del PJD en Marruecos: la marcha islámica de 2000 y el debate sobre las mujeres", Revista de Estudios Internacionales Mediterráneos, oㅡ 22. : DOI: https://doi.org/10.15366/reim2017.22.001.

PROFIL (2014): Profil genre de la Tunisie, Túnez, disponible en : http://eeas.europa.eu/archives/delegations/tunisia/documents/page content/profil genretunisie 2014 courte fr.pdf [consulta: 20 de julio de 2018].

RUIZ DE ALMODÓVAR, Caridad (2005): El derecho privado en los países árabes. Códigos de estatuto personal, Granada, Universidad.

SCOTT, James C. (2000): Los dominados y el arte de la resistencia, México DF, Era.

SRAÏEB, Noureddine (1967): "Contribution à la connaissance de Tahar el Haddad (1899-1935)", Revue de l'Occident Musulman et de la Méditerranée, no 4, pp. 99-132. DOI: https://doi.org/10.3406/remmm.1967.965

STRATEGIE (2012): Stratégie Nationale de lutte contre les violences faites aux femmes (VFF) à travers le cycle de vie, Túnez, Ministère des Affaires de la Femme et de la Famille, UNFPA, 2012, disponible en: http://tunisia.unfpa.org/sites/default/files/pubpdf/STRATEGIE\%20VIOLENCE\%20fr.pdf [consulta: 21 de julio de 2018].

TUBERT, Silvia (2003): "La crisis del concepto de género", en S. TUBERT, Silvia (ed.), Del sexo al género. Los equívocos de un concepto, Madrid, Cátedra-Universitat de València, Instituto de la Mujer, 2003, pp. 7-38.

YOUSSFI, Imane (2017): "Tunisie: une loi historique contre les violences faites aux femmes adoptée", Saphir News, disponible en: https://www.saphirnews.com/Tunisie-une-loi-historiquecontre-les-violences-faites-aux-femmes-adoptee a24253.html [consulta: 22 de julio de 2018]. 